\title{
Field Performance Assessment of Synthetic Liners for Uranium Tailings Ponds: A Status Report
}

D. H. Mitchell

G. E. Spanner

March 1984

Prepared for the

U.S. Nuclear Regulatory Commission

under Contract DE-AC06-76RLO 1830

Pacific Northwest Laboratory

Operated for the U.S. Department of Energy

by Battelle Memorial Institute 


\title{
DISCLAIMER
}

This report was prepared as an account of work sponsored by an agency of the United States Government. Neither the United States Government nor any agency thereof, nor any of their employees, makes any warranty, express or implied, or assumes any legal liability or responsibility for the accuracy, completeness, or usefulness of any information, apparatus, product, or process disclosed, or represents that its use would not infringe privately owned rights. Reference herein to any specific commercial product, process, or service by trade name, trademark, manufacturer, or otherwise, does not necessarily constitute or imply its endorsement, recommendation, or favoring by the United States Government or any agency thereof. The views and opinions of authors expressed herein do not necessarily state or reflect those of the United States Government or any agency thereof.

\author{
PACIFIC NORTHWEST LABORATORY \\ operated by \\ BATTELLE \\ for the \\ UNITED STATES DEPARTMENT OF ENERGY \\ under Contract DE-AC06-76RLO 1830
}

Printed in the United States of America
Available from
National Technical Information Service
United States Department of Commerce
5285 Port Royal Road
Springfield, Virginia 22161
NTIS Price Codes
Microfiche A01
Printed Copy
Pages
$001-025$
$026-050$
$051-075$


FIELD PERFORMANCE ASSESSMENT

OF SYNTHETIC LINERS FOR URANIUM

TAILINGS PONDS: A STATUS REPORT

D. H. Mitchell

G. E. Spanner

March 1984

Prepared for

the U.S. Nuclear Regulatory Commission

Office of Nuclear Materials Safety and Safeguards

Division of Waste Management

under Contract DE-AC06-76RL0 1830

NRC FIN B2476

Pacific Northwest Laboratory

Richland, Washington 99352 


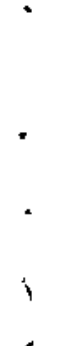

, 


\section{ACKNOWLEDGMENTS}

This program is sponsored by the U.S. Nuclear Regulatory Commission's Low Level and Uranium Recovery Projects Branch, Division of Waste Management. The NRC Project Manager is Roger A. Pennifili.

The authors wish to acknowledge the following individuals and organizations who have contributed to this program:

- G. P. Giroud, J. S. Goldstein, and C. Ah-Line, Woodward-Clyde Consultants, Chicago, illinois, for providing information on failures of lined tailings and evaporation ponds and failure prevention measures

- R. K. Frobel, U.S. Bureau of Reclamation, Engineering and Research Center, Denver, Colorado, for cooperation in the field demonstration of seam inspection devices

- R. Newton and P. Arms, Northwest Linings, Seattle, Washington, for assistance with fabrication of sample seams for nondestructive testing

- S. E. King, Pacific Northwest Laboratory, for report editing

- J. Morrey, Pacific Northwest Laboratory, for differential infrared spectroscopy

- R. N. Gordon, Pacific Northwest Laboratory, for liner testing

- J. C. Harris, Pacific Northwest Laboratory, for assistance in laboratory and field seam inspection. 


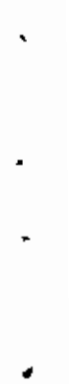

. 


\section{SUMMARY}

The objective of this study is to provide a database to support U.S. Nuclear Regulatory Commission (NRC) licensing of uranium tailings leachate isolation impoundments. This objective is being accomplished by determining the effectiveness of design, installation, and quality assurance practices associated with uranium mill tailings impoundments with flexible membrane liners. The program includes testing of chemical resistance and physical performance of iners, leak detection systems, and seam inspection techniques.

This report presents the status of the program through September 1983. The report addresses impoundment design, installation, and inspection techniques used by the uranium milling industry. To determine the relative successes of these techniques, information has been collected from consultants, mill operators, and the synthetic liner industry. Progress in experimental tasks on chemical resistance of liners, physical properties of liners, and nondestructive examination of seams is reported.

The following are major accomplishments during fiscal year 1983:

- Case histories for failures of impoundments with synthetic liners were compiled through analysis of available literature and discussions with mill operators and specialists in the liner industry. From this work a variety of fatlure mechanisms were ranked according to frequency of occurrence. From this ranking, quality assurance efforts can be concentrated in the areas of design and construction that are most critical for proper performance of the pond.

- Liner aging columns were designed and built. Exposure tests with high density polyethylene and polyvinyl chloride samples in a simulated tailings environment were completed. Chemical tests showed that very littie chemical degradation of the high density polyethylene had occurred after 18 weeks of exposure at elevated temperatures. Physical tests showed a slight increase in tensile 
strength and tear resistance, and no loss of seam strength or puncture resistance on aged samples. Physical and chemical tests on the polyvinyl chloride liner samples are underway.

- Seam inspection techniques were evaluated and an experimental program investigating novel nondestructive seam inspection techniques was completed. The study successfully demonstrated two systems capable of nondestructive examination of seams for lack of bond. A pulse-echo ultrasonic device worked well on field seams of nonreinforced materials. An ultrasonic impedance plane technique that works well on both reinforced and nonreinforced geomembrane seams was demonstrated. Both devices were tested in the laboratory and under field conditions.

- Leak detection systems were evaluated for uranium tailings and evaporation ponds. Experiments with three alternative systems were also conducted. The results of the leak detection work have been published (Myers et a1. 1983). 


\section{CONTENTS}

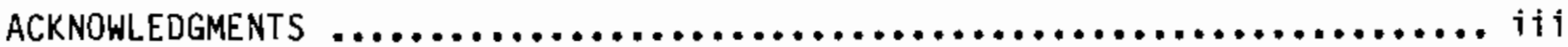

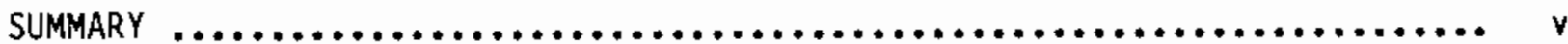

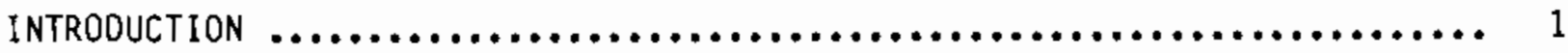

CONCLUSIONS AND RECOMMENDATIONS $\ldots \ldots \ldots \ldots \ldots \ldots \ldots \ldots \ldots \ldots \ldots \ldots \ldots \ldots, 3$

LINED IMPOUNDMENT FAILURE MECHANISMS $\ldots \ldots \ldots \ldots \ldots \ldots \ldots \ldots \ldots \ldots \ldots \ldots, \ldots \ldots \ldots$

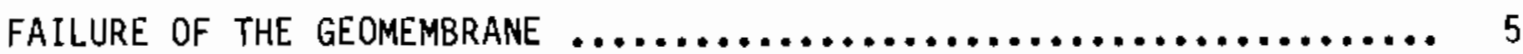

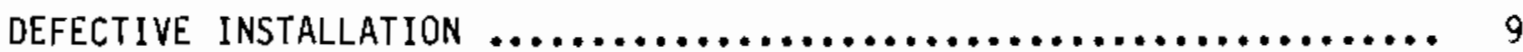

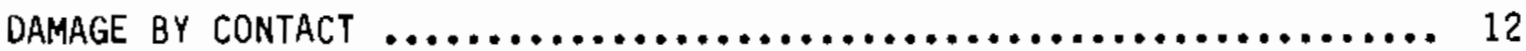

GAS AND LIQUID DAMAGE $\ldots \ldots \ldots \ldots \ldots \ldots \ldots \ldots \ldots \ldots \ldots \ldots \ldots \ldots \ldots, 12$

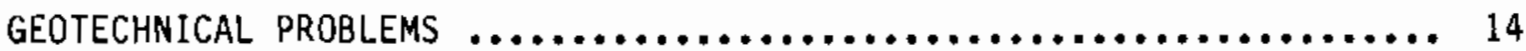

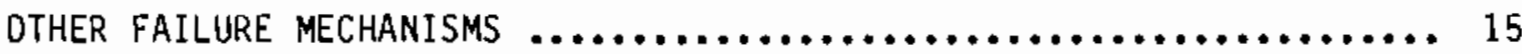

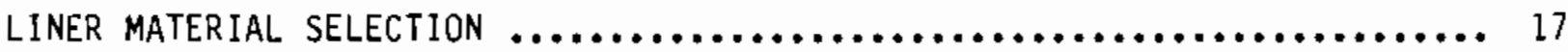

CHEMICAL REACTIVITY $\ldots \ldots \ldots \ldots \ldots \ldots \ldots \ldots \ldots \ldots \ldots \ldots \ldots \ldots \ldots, 17$

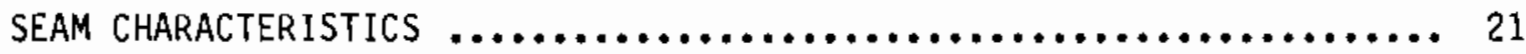

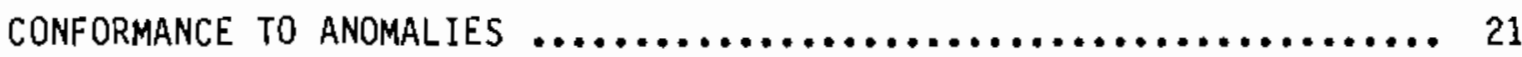

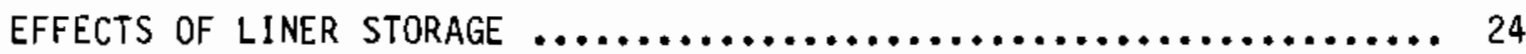

IMPOUNDMENT DESIGN AND INSTALLATION PRACTICES $\ldots \ldots \ldots \ldots \ldots \ldots \ldots \ldots \ldots ., 25$

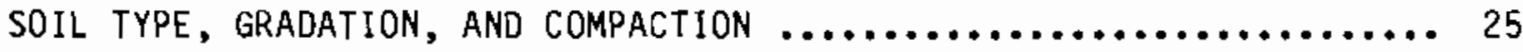

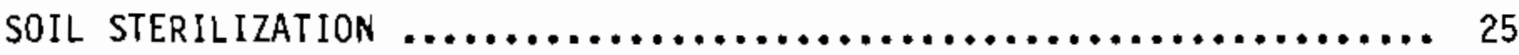

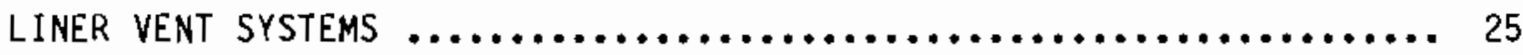

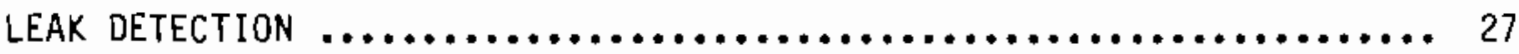

SOIL COVERS FOR LINERS $\ldots \ldots \ldots \ldots \ldots \ldots \ldots \ldots \ldots \ldots \ldots \ldots \ldots \ldots \ldots, 27$

NONOESTRUCTIVE INSPECTION TECHNIQUES FOR SYNTHETIC LINER SEAMS $\ldots \ldots \ldots \ldots ., 31$

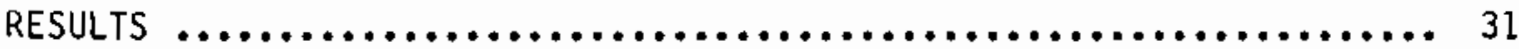




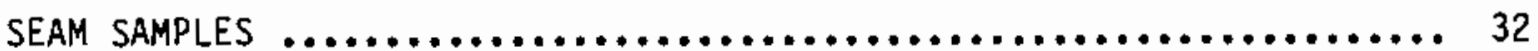

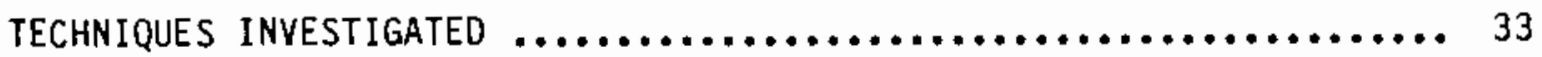

ULTRASUNIC IMPEDANCE PLANE INSTRUMENT $\ldots \ldots \ldots \ldots \ldots \ldots \ldots \ldots \ldots \ldots . \ldots \ldots$

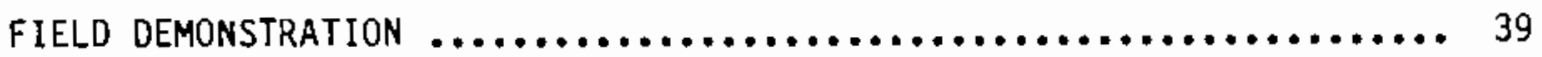

REQUIREMENTS FOR IMPLEMENTATION $\ldots \ldots \ldots \ldots \ldots \ldots \ldots \ldots \ldots \ldots \ldots \ldots, 42$

ACCElERATED AGING TESTS $\ldots \ldots \ldots \ldots \ldots \ldots \ldots \ldots \ldots \ldots \ldots \ldots \ldots \ldots \ldots \ldots \ldots \ldots \ldots \ldots$

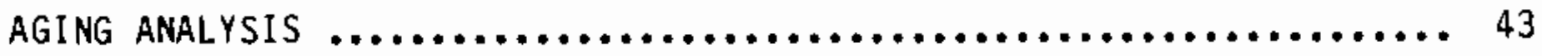

COLUMN DESCRIPTION $\ldots \ldots \ldots \ldots \ldots \ldots \ldots \ldots \ldots \ldots \ldots \ldots \ldots \ldots \ldots \ldots \ldots, 45$

EXPERIMENTAL PROCEDURE $\ldots \ldots \ldots \ldots \ldots \ldots \ldots \ldots \ldots \ldots \ldots \ldots \ldots \ldots \ldots, 47$

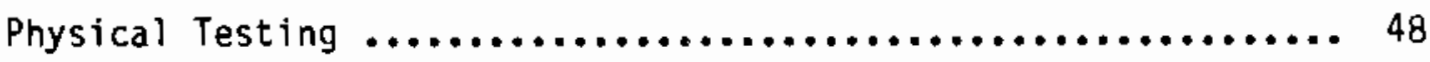

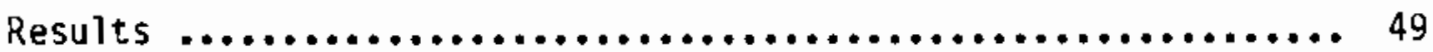

ANOMALY CONFORMANCE TESTS $\ldots \ldots \ldots \ldots \ldots \ldots \ldots \ldots \ldots \ldots \ldots \ldots \ldots \ldots \ldots \ldots \ldots \ldots \ldots$

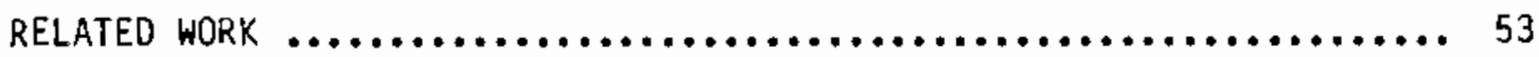

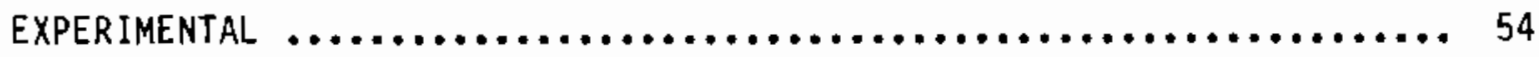

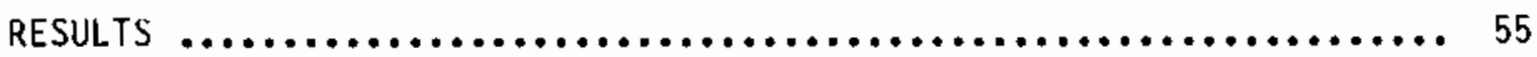

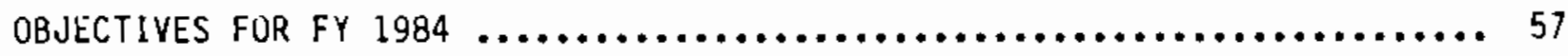

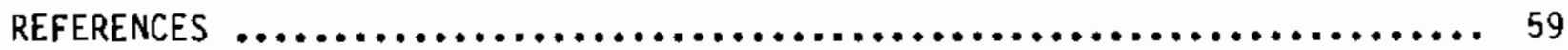

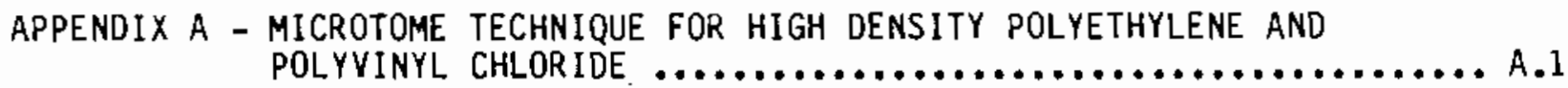
APPENDIX B - PHYSICAL TESTING PROCEDURES $\ldots \ldots \ldots \ldots \ldots \ldots \ldots \ldots \ldots \ldots \ldots \ldots$. APPENDIX C - COLUMN CONDITIONS DURING HIGH DENSITY POLYETHYLENE EXPOSURE TESTS $\ldots \ldots \ldots \ldots \ldots \ldots \ldots \ldots \ldots \ldots \ldots, \ldots .1$ APPENDIX D - SCHEMATICS FOR FAULTY SEAMS FOR SEAM INSPECTION TESTS ...... D.1 


\section{FIGURES}

1 Typical Configurations of Geomembrane Field Seams ............... 23

2 Air Lance Detecting an Unbond in a Chlorosulfonated Polyethylene Seam ........................................ 34

3 Vacuum Chamber Detecting a Leak in a Chlorosulfonated Polyethylene ............................................. 35

4 Sketches of a Typical Pulse-Echo Ultrasonic Screen Display for a) a Well-Bonded Seam and b) a Faulty Bond of a Nonreinforced Material

5 PNL Designed Holder for the Ultrasonic Impedance Plane Instrument $\ldots 41$

6 Seam Inspection Transducer Holder with the Uitrasonic Impedance Plane Instrument ................................ 41

7 Schematic of Accelerated Aging Column ...................... 46

8 Results of Differential Infrared Analysis of Aged High Density Polyethylene Samples Indicating Relative Carbonyl Concentrations .... 51

9 Schematic of Anomaly Conformance Test Device ................... 54 


\section{TABLES}

1 Failure Mechanisms of Impoundments Lined with Geomembranes ......... 6

2 Failure Mechanisms in Order of Declining Frequency ............. 7

3 Uranium Mill Leachate Compositions $\ldots \ldots \ldots \ldots \ldots \ldots \ldots \ldots \ldots \ldots \ldots \ldots$

4 Typical Seam Characteristics of Various Geomembranes .............. 22

5 Liner Properties that are Important for Resisting Failure Due to Stresses Created by Subgrade Anomalies ..................... 23

6 Subgrade Preparation Procedures Practiced at Some Uranium Milis ..... 26

7 Characteristics of Soil Covers at Lined Uranium Tailings Ponds ...... 28

8 Simulated Leachate Composition $\ldots \ldots \ldots \ldots \ldots \ldots \ldots \ldots \ldots \ldots \ldots \ldots \ldots \ldots . \ldots . \ldots$

9 Average Exposure Conditions of High Density Polyethylene Samples .... 49

10 Results of Differential Scanning Calorimetry on Virgin and Aged High Density Polyethylene Samples ................... 50

11 Results of Shear Tests on Fillet-Welded Lap Seams of Virgin and Aged High Density Polyethylene .................... 52

12 Results of Tear Tests on Virgin and Aged High Oensity Polyethylene .......................................... 52

13 Results of Tests Stressing $1 \mathrm{~mm}$ High Density Polyethylene and $0.91 \mathrm{~mm}$ Polyvinyl Chloride Over a Rocky Subgrade 56 


\section{INTRODUCTION}

Uranium milling operations produce spent leachate, either acidic or basic, which has been traditionally disposed by a combination of seepage and evaporation from ponds or pits. Current environmental regulations require the use of synthetic liners to prevent migration of contaminants from ponds to the groundwater. Polymeric pond liners being used to meet regulations are prone to a variety of failure modes due to improper design, installation, and operation. Because of concern for proper performance of ponds with synthetic membrane liners (or geomembranes), the Pacific Northwest Laboratory (PNL) was contracted by the U.S. Nuclear Regulatory Commission to provide information required to support licensing of active uranium mill impoundments with synthetic membrane liners.

PNL has compiled data on impoundments with flexible membrane liners and has undertaken an experimental program to provide the required database. This report discusses failure mechanisms which have been identified and ways to avoid these mechanisms. Design and installation practices at existing lined uranium mill ponds are reported. The findings of an experimental task investigating seam inspection techniques are presented. Finally, the status of accelerated aging tests with synthetic liners and physical performance tests with these aged liners is reported. 



\section{CONCLUSIONS AND RECOMMENDATIONS}

Failure mechanisms which have been identified for impoundments with synthetic membrane liners can be avoided or their frequencies reduced at uranjum mill tailings ponds. Proper design, installation, and quality assurance procedures, which are discussed in the report, can assure high quality impoundments.

The most common liner failure mechanism is faulty seams. Two nondestructive techniques (ultrasonic impedance plane and pulse-echo ultrasonics) can be used to inspect field seams with more reliability than presently used methods. implementation of these devices is recommended to reduce the frequency of faulty seams.

Failure mechanisms which have been reported or observed at uranium mill ponds with geomembranes in the U.S. include gas uplift, sloughing of soil covers, and bank deformation. Gas uplift can be entirely avoided by the vent systems described in this report. Sloughing of soil covers can be reduced by using clay-silt soils on banks with $33 \%$ or less slopes, and bank deformation can be reduced by proper drainage and by designing the impoundment with narrow dimensions in the direction of prevailing winds. Means to reduce the occurrence of other failure mechanisms are described in this report.

Based on accelerated aging tests in a simulated uranium tailings environment, high density polyethylene appears to be a suitable liner material for uranium mill tailings ponds containing acidic leachate. No significant chemical or physical changes in the material were observed after 18 weeks of exposure at elevated temperature. Tests with other liner materials are still in progress. 


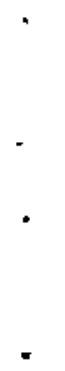




\section{LINED IMPOUNDMENT FAILURE MECHANISMS}

To better document recent experience with synthetically lined impoundments, PNL subcontracted with Woodward-Ciyde Consultants, a firm with broad experience in investigations of impoundment failures. The consultant provided information on lined liquid impoundment failures, ranked the frequency of failure mechanisms and reported on means to avoid these failures. PNL engineers also have performed an extensive literature search and talked with uranium mill operators. This section reports the findings on failure mechanisms, especially as they apply to uranium tailings ponds.

The subcontractor on this project provided out 1 ines of failure mechanisms at 29 lined, liquid impoundments. Kays (1977) has also reported impoundment failure mechanisms. In discussions with uranium mill operators, PNL. researchers identified failure mechanisms which have occurred at U.S. mills with geomembranes. These failure mechanisms, listed in Table 1, have been grouped into six categories. Mechanisms in each category are briefly described and avoidance methods are discussed.

When examining these mechanisms, note that many are interrelated and one may lead to another. Eventually catastrophic failure of the impoundment may result. It should also be noted that some liner materials are prone to certain problems more than others. Therefore, when selecting a geomembrane and designing a pond, a designer must address important mechanical properties of the liner in addition to its chemical resistance.

Failure mechanisms are rated according to their relative frequency based on experience in designing and inspecting lined impoundments and landfills, conferences and publications on the subject, and interviews with designers and installers. In order of declining frequency, the most commonly occurring mechanisms are listed in Table 2.

FAILURE OF THE GEOMEMBRANE

Manufacturing defects include nonuniform selvage, pinholes, insufficient ply adhesion, and chemical defects. Selvage is the nonreinforced edge of a 
TABLE 1. Failure Mechanisms of Impoundments Lined with Geomembranes

$\begin{array}{lc}\text { Failure of Geomembrane } & \text { Gas and Liquid Damage } \\ \text { Manufacturing defects } & \text { Gas uplift } \\ \text { Weathering } & \text { Wind } \\ \text { Physical } & \text { Waves } \\ \text { Chemical } & \text { Liquid uplift } \\ \text { Mechanical } & \text { Overtopping } \\ \text { Oefective Installation } & \text { Geotechnical Problems } \\ \text { Storage } & \text { Slope instability } \\ \text { Transportation } & \text { Sloughing of cover material } \\ \text { Placement } & \text { Subsidence } \\ \text { Seaming } & \text { Differential settlement } \\ \text { Appurtenances } & \text { Expansive clays } \\ \text { Placement of cover materials } & \text { Dther Failure Mechanisms } \\ \text { Damage by Contact } & \text { Vandalism } \\ \text { Puncture } & \text { Seismic activity } \\ \text { Vegetation } & \\ \text { Shocks } & \end{array}$

reinforced material that is required to prevent absorption of liquid (wicking) between plies of a geomembrane. Apparently the selvage width is difficult to maintain in the factory. Nonuniform selvage can cause seaming difficulties because a selvage that is too wide will result in seams without any scrim, which are very weak. In contrast, a selvage that is too narrow can expose the scrim and cause wicking between plies, leading to delamination.

Pinholes are usually the result of recycling of liner scraps with scrim in the factory, a practice that has largely been eliminated. Pinholes may also be caused by dust in the factory. Leakage due to pinholes is minor compared to leakage created by higher-frequency failure mechanisms.

Insufficient ply adhesion is a manufacturing problem for reinforced materials. Periodic destructive tests at the factory are the best way to monitor ply adhesion. 
TABLE 2. Failure Mechanisms in Order of Declining Frequency

1. Seaming

2. Shocks and errors during placement

3. Connections to appurtenances

4. Puncturing by cover materials and anomalies

5. Liquids in support soil - slope instability, subsidence, bank erosion by waves, underpressures

6. Wind

7. Lack of knowledge about mechanical properties

8. Degradation by chemicals

9. Localized subsidence, cracks

10. Transportation, storage

11. Uplift by gases

12. Slope and cover movements

13. Delamination, blistering

14. Vandalism

15. Vegetation

16. Animals

17. Pinholes

Chemical defects are inconsistencies in the chemical composition of a geomembrane. Since these defects are difficult to monitor or control, chemical and physical testing at the factory are the best ways to check the chemical consistency of a liner.

Weathering refers to chemical and physical changes in a liner as a result of sunlight, temperature, humidity, and soil contact. Common weathering problems include ozone deterioration of butyl rubber under tension, loss of plasticizers in polyvinyl chloride by heat and soil absorption, and ultraviolet degradation of polyvinyl chloride. A designer must take weathering characteristics into account in liner selection and impoundment design.

Physical failure mechanisms include shrinkage, thermal expansion and contraction, and delamination and blistering. Polyvinyl chloride is the liner most prone to shrinkage. Reinforced liners do not experience this problem. 
Polyvinyl chloride shrinkage problems can be minimized by manufacturing techniques that do not allow tension during manufacturing. In the field the polyvinyl chloride sheets should not be stretched, but should be installed with slack.

High density polyethylene has a thermal expansion coefficient that is an order of magnitude higher than other geomembranes. This material is prone to bulge or ripple when heated by solar radiation. The expansion, coupled with its relative stiffness, can create stresses that can damage the liner, especially at seams. A high density polyethylene installer states that to avoid problems created by thermal expansion and contraction, seams should be made when the material is not expanded (at night if necessary). The stresses which occur at seams during subsequent expansion will not be a problem if the peel strength of the seam is adequate. Expansion can be reduced by using a soil cover.

Delamination of a reinforced liner across the width of a panel will result in geomembrane failure. The potential for leaks by this mechanism is highest at corners of a pond, where the distance between panels is small. To reduce this potential, all slant seams (seams with cuts at an angle to the scrim) should be covered with a cap strip. Ply adhesion tests will indicate the relative resistance of liners to delamination. After installation of reinforced liners, all seams and patches should be examined to assure that no scrim is exposed, because exposed scrims can lead to wicking and delamination. Exposed scrims should be painted with an appropriate material.

Blistering is a rare problem in which a localized delamination or gas bubble exists between two plies of a liner. Because the blister does not grow, it is not a very serious problem.

Chemical failures of geomembranes have become relatively uncommon because of increased information on chemical compatibility. There are unique situations, however, in which chemical damage may occur. For example, evaporation of water from a pond containing trace hydrocarbons, which are harmless in a dilute state, may leave concentrated hydrocarbons that can damage the liner. Spillage of seaming solvents, gasoline, or oil can also damage a liner during construction of an impoundment. Adhesives used for seaming which are 
incompatible with the chemicals to be held in the impoundment can lead to failure of the seams. Chemical compatibility is also addressed later in this report in the discussion of various types of liners and in the section on accelerated liner aging.

Mechanical failures are due to stresses on the liner. Giroud and Goldstein (1982) state that liners can be divided into two categories according to their mechanical properties. The first category comprises liners with high tensile strength and low elongation, such as reinforced geomembranes and a few nonreinforced, stiff geomembranes with 10 to $20 \%$ elongation. This class of liners is recommended where high stresses are expected, such as sites with steep slopes or sites where gas uplift may occur. The second category is geomembranes with low tensile strength but large elongation (nonreinforced elastomers), which are applicable at sites where subsidence and differential settlement may be a problem.

DEFECTIVE INSTALLATION

Geomembrane failures due to defective installation include storage and transportation damage, placement damage, faulty seams, connections to appurtenances, and placement of cover materials.

Improper storage can cause problems for certain geomembranes. Membranes sensitive to ultraviolet radiation should be stored in the dark. In hot climates plasticizers will migrate from polyvinyl chloride. Chlorosulfonated polyethylene will cure at elevated temperatures, causing embrittlement or adhesion of adjacent layers. If these materials are at hot sites, air conditioned storage is advisable.

With regard to transportation both from manufacturer to fabricator and from fabricator to the site, there is potential for damage by crates, nails, forklifts, and other machinery. This problem can be avoided by monitoring transportation activities and by inspecting the geomembranes.

Damage during placement includes shocks and installation under tension. Polyvinyl chloride is particularly prone to the latter problem because of its shrinkage tendency. If installed initially under tension, subsequent shrinkage 
will create more tension that can lead to failure. Polyvinyl chloride liners should therefore be installed with slack or wrinkles. This practice, however, does make seaming more difficult.

The most frequent failure mechanism listed previously in this section was faulty seams. Field seams are typically made at 6-m intervals; therefore, a $80,000 \mathrm{~m}^{2}$ (20 acre) pond has roughly $13 \mathrm{~km}$ ( $8 \mathrm{miles}$ ) of field seams. Thus there is a critical need to attain high-quality field seams in a liner.

Causes of faulty seams obtained from information provided by consultants and from Kays (1977) include:

- improper adhesive system

- defective adhesive

- surface contamination

- improper tack development before closure

- moisture or high humidity

- improper temperature

- inadequate contractor experience

- improper layout

- solvent evaporation from adhesive

- lack of necessary bonded width

- unbonded edges

- three-layer seans

- seams of two different materials.

Some of these problens are self-explanatory and can be avoided by proper quality assurance requirements and enforcement of these requirements. However, some less obvious design techniques that can contribute to more successful seaming are discussed.

The layout of a pond should not have seams perpendicular to the slope of the embankment. If subsidence of a dike or sloughing of a cover or dike occurs, a perpendicular seam is stressed more than a seam parallel to the slope.

Seaming of three layers of material is very undesirable and should be avoided if possible. Where this is not possible, the triple seam should be covered with a patch. 
Seaming two different kinds of materials together is difficult. We are aware of sites where polyvinyl chloride was seamed to chlorinated polyethylene. The polyvinyl chloride aged, shrunk, and cracked at the seams. The practice of using different materials in one pond is not recommended for this reason.

Several materials, particularly butyl rubber, ethylene-propyleneterpolymer and ethylene-propylene-diene monomer, are prone to seam defects called "fishmouths." These are created when unequal tensions in two sheets being seamed cause the sheet with lower tension to pop up at intervals along the seam. When fishmouths form they must be cut out and patched.

Because seaming is such an important factor in building a successful pond, quality control efforts should be maximized during field seam fabrication and inspection. This project investigated field seam inspection techniques, and results of that investigation are discussed in a subsequent section. Because factory seams have also been faulty, quality control at the factory during seaming may be necessary in the overall quality control plan.

Failures frequently occur at connections to submerged appurtenances (such as concrete structures or steel pipes) in lined liquid impoundments. If a uranium pond calls for appurtenances, proper design and installation can reduce the failure potential. Because elongation is a desirable property due to the potential for differential settlement, an appropriate geomembrane should be used and installed with slack if possible. Subgrade preparation to reduce potential for subsidence and differential settlement is needed. Field inspection of the completed connection is vital.

Cover materials, although useful in preventing many liner problems, can also create problems during placement. Puncture by stones in the cover soil or in subgrade may occur. Vehicles operating on the cover may puncture or tear the liner. Cover installation methods will be discussed later in this section. 


\section{DAMAGE BY CONTACT}

As just mentioned, stones, crystals, and other sharp objects both above and below a liner may danage it. Preventative measures include raking and subgrade compaction, installation of a sand layer, and placement of a geotextile below the liner.

Vegetation both above and below liners is a potential failure mechanism. Proper clearing and sterilization techniques can prevent weed growth beneath the liner. Above a liner, proper maintenance can prevent damage from vegetation.

Shocks by foreign objects such as tools, cigarettes, hot seaming equipment, foot traffic, vehicles, sharp-hoofed animals, burrowing animals, floating ice and debris, and hail can damage geomembranes. For example, at a site visited during this project, wind had demolished a wood float in the pond. Debris from the float had collected at the edge of the pond, which potentially could puncture the uncovered liner. Because of these factors, appropriate preventative measures need to be taken. Soil covers can be effective in preventing many of these problems. In addition, inspection, operation, and maintenance rules are needed.

Impingement of tajlings on the liner can erode the membrane. One uranium mill operator described such an occurrence. A tailing discharge line ruptured and a jet of tailings and leachate bored a hole through the liner. Fortunately, this mechanism would likely occur in a location permitting repair. Discharge lines should be located where the normal discharge will not damage the liner.

GAS AND LIQUID DAMAGE

Gas uplift can occur in uncovered ponds with improper venting due to gases generated by organic decay, air displaced by a rising water table, air trapped from installation, and gas generated by leaking liquid. In the case of acidic uranium tailings, carbon dioxide is released by neutralization of acid with carbonates in the soil. Several documented cases of gas uplift exist in the literature (Giroud 1982; Giroud and Goldstein 1982). Soil covers are usually 
effective in eliminating gas uplift; however, one uranium mill has experienced gas uplift in evaporation ponds even though soil covers $0.3-m$ thick have been used. One site visited in this study had a soil cover that had slid down the embankment. It was obvious that gases were trapped in the bank, which made bulges in the liner in warm weather. Gas uplift can easily be avoided with a properly designed subgrade venting system.

Wind can damage liners during installation and prior to filling (if not covered). Wind is also responsible for damage due to waves. Wind damaged a liner during installation at one uranium mill contacted in this study. There is no way to avoid this problem except by anchoring the liner with tires, sandbags, or sandfilled tubes (Baldwin 1983) and trying to avoid construction when high winds are probable. Once the liner is in place, wind effects can be minimized by a soil cover, by filling the pond, by using anchor trenches (Giroud 1977), and by placing vents on the top of the dike which reduce pressure below the liner, thereby holding the liner down.

Waves can damage geomembranes by fatigue, abrasion, shocks against stones, sloughing of cover materials, and deformation of the dike under the liner. Waves can also cause dike damage by overtopping. Several uranium mill ponds investigated in this study have experienced wave erosion of cover materials and bank deformation. At one site, the liners on the slope had ripped, apparently because of bank deformation.

Damage by waves can be reduced by building ponds with a narrow dimension in the direction of the prevailing winds. Deeper ponds are less prone to large waves. Kays (1977) tabulates wave heights as functions of wind velocity and fetch in reservoirs. This information is useful in determining the minimum freeboard requi rements for ponds.

Riprap can prevent cover erosion by waves. This technique is used at one uranium mill pond; however, the pond level has never reached the riprap layer.

If dike soil is kept dry, stability of the dike is increased and wave damage is less probable. Therefore it may be desirable to place the geomembrane 
over the dike and under the usuat perimeter road. An associated advantage of this methodology is elimination of requirements for anchor trenches.

Liquid underpressures from springs or a rising water table can stress geomembranes. The primary means of avoiding liquid underpressures is to provide adequate liquid drainage. Uranium mills are currently using drain-type leak detection systems, which should be adequate for this function. However, there are several potential drawbacks associated with drain pipes: they can collapse or become plugged; and sand-gravel layers may be displaced before, during, and after liner installation. Plastic nets are gaining popularity for liquid drainage in lined impoundments.

GEOTECHNICAL PROBLEMS

Slope instability is a failure mechanism that can be avoided by proper dike engineering. Recommendations for dike construction to prevent this occurrence are available from numerous sources.

The sloughing of soil covers can damage the geomembrane. In addition, the protective function of the soil cover is then lost and additional failure mechanisms may occur.

Localized subsidences are either circular (0.5- to $1.0-\mathrm{m}$ diameter by up to 1-m deep) or rectangular (0.3-m by several meters and up to $1-\pi$ deep). They are primarily due to erosion or chemical attack of the soil in the subgrade. The best way to prevent subsidences is by proper geotechnical examination of the site and proper subgrade drainage. In addition to a proper subgrade, failure potential can be reduced by choice of a geomembrane with or without a geotextile with stress-strain characteristics that will survive typical subsidences as outlined by Giroud (1982). Smaller subsidences can be caused by collapse of underdrains.

Differential settlements occur around appurtenances. The probability of this type of failure can be reduced by proper soil compaction around the appurtenance and proper liner selection. Appurtenances in uranium mill ponds should be avoided if possible because of the frequency of this type of failure. 
Certain clays that may comprise the subgrade can expand or shrink when wet. Synthetic flexible liners can survive expansion or shrinkage of subgrade clays as long as structures are not in the system and the transition from clay to undisturbed native soil is gradual.

\section{OTHER FAILURE MECHANISMS}

Vandalism can be a problem at any pond with a geomembrane; however, most uranium milling facilities are remotely located and vandalism is unlikely. Soil covers can reduce the risk of damage to a liner by vandals.

Seismic activity could damage lined impoundments by several mechanisms. 0ikes built of noncohesive soil are unstable in earthquakes, and waves generated by earthquakes can damage dikes. In general, the flexible liner is not directly damaged by sejsmic activity. 


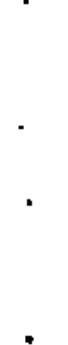

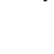


LINER MATERIAL SELECTION

Many factors need be considered when selecting a geomembrane. This section discusses data compiled on the chemical, mechanical, and seaming characteristics of various liners which may be used at uranium mill tailings ponds.

\section{CHEMICAL REACTIVITY}

A geomembrane must be chosen for a pond on the basis of chemical resistance to materials in the leachate and resistance to weathering due to normal atmospheric conditions. Information was collected from mill operators and the iiterature on the chemical composition of acidic uranium tailings leachate. Additionally, liner manufacturers and the literature provided the general characteristics of various liner materials. Finally, in the laboratory a testing program is underway to age selected liner materials under accelerated conditions to simulate approximately 20 years of finer aging and to measure changes in physical and chemical properties. This section of the report discusses the chemical composition of uranium tailings leachate and the reported properties of various geomembranes. The aging of the liners in acidic leachate is discussed in a subsequent section of the report.

Compositions of various acidic leachates are listed in Table 3. The major constituents are water and sulfuric acid. Other listed components are primarily dissolved metallic cations. Ammonia may be present because it is used to precipitate yellowcake in the process. Radionuclides are also present in small amounts. The pH of spent leachate ranges from 1 to 2 .

Organic constituents in the leachate are not reported in the literature, though trace amounts may be present. Typically organics such as kerosene, alkyl amine, and alcohol are used to remove uranium from the pregnant leachate (US NRC 1980). The fate of these organics in the milling process requires further investigation. According to Williams (1982), kerosene is the only organic component that could threaten a liner at a tailings pond. He states that kerosene should not be allowed to contact a chlorosulfonated polyethylene liner. 
TABLE 3. Uranium Mill Leachate Compositions(a)

\begin{tabular}{|c|c|c|c|c|}
\hline $\begin{array}{c}\text { Major } \\
\text { Species }\end{array}$ & $\begin{array}{l}\text { Highland } \\
\text { Mill (D) }\end{array}$ & $\begin{array}{l}\text { NRC Model } \\
\text { Mill (c) }\end{array}$ & $\begin{array}{l}\text { EPA TRU } \\
\text { values (c) }\end{array}$ & $\begin{array}{l}\text { Sweetwater } \\
\text { Mill (d) }\end{array}$ \\
\hline $\begin{array}{l}\mathrm{Al} \\
\mathrm{As} \\
\mathrm{Ca} \\
\mathrm{Cd} \\
\mathrm{Cl} \\
\mathrm{Cr} \\
\mathrm{Cu} \\
\mathrm{F} \\
\mathrm{Fe} \\
\mathrm{Hg} \\
\mathrm{K} \\
\mathrm{Mg} \\
\mathrm{Mn} \\
\mathrm{Mo} \\
\mathrm{Na} \\
\mathrm{NH} \\
\mathrm{Ni}_{3} \\
\mathrm{P} \\
\mathrm{Pb} \\
\mathrm{Se} \\
\mathrm{Si} \\
\mathrm{SO}_{4} \\
\mathrm{~V} \\
\mathrm{Zn}\end{array}$ & $\begin{array}{l}688 \\
63.5 \\
<5 \\
343 \\
3 \\
30 \\
<1 \\
233.5 \\
12850 \\
8.4\end{array}$ & $\begin{array}{l}2000 \\
3.5 \\
500 \\
0.2 \\
300 \\
\\
50 \\
5 \\
1000 \\
0.07\end{array}$ & $\begin{array}{l}700-1600 \\
0.2 \\
1.4-2.1 \\
0.08-5 \\
0.02-2.9 \\
0.7-8.6 \\
300-3000\end{array}$ & $\begin{array}{l}151-180 \\
0.4 \\
61-127 \\
\text { ND } \\
40-100 \\
2.0 \\
1.0 \\
0.5-1.6 \\
495-1350 \\
0.004 \\
1-610 \\
124 \\
23 \\
0.1 \\
100-109 \\
1.3 \\
0.05-0.09 \\
<1 \\
0.03 \\
186-281 \\
9312-9529 \\
2.8-3.2 \\
1.6-31\end{array}$ \\
\hline $\mathrm{pH}$ & 1.8 & 2.0 & & $0.9-1.99$ \\
\hline
\end{tabular}

Radionuclides, $\mathrm{pCi}$ /L

$\begin{array}{lll}\mathrm{Pb}-210 & 250 & 1541 \\ \mathrm{Po}-210 & 250 & 361 \\ \mathrm{U} & 3300 & 5.4(\mathrm{ppm}) \\ \mathrm{Ra}-226 & 250 & 47.99 \\ \mathrm{Th}-230 & 90,000 & 3035 \\ \mathrm{Bi}-210 & 250 & \end{array}$

ND = none detected

a) Values in parts per million (ppm).

b) Gee et al. (1980).

c) US NRC (1980).

d) from site visit. 
There is a large variety of potential liner materials for uranium tailings ponds. In this section, the most common and promising materials will be discussed.

High density polyethylene is a relatively new material on the market. It should not be confused with low density polyethylene because it has markedly different properties. High density polyethylene is also called linear polyethylene. A stiff, nonreinforced geomembrane with about $2 \%$ carbon black added to resist ultraviolet aging, it also resists most chemicals. This material is available in unseamed sheets 1 - to 3 -mon thick and up to 10-m wide, eliminating requirements for factory seams. In the field, it is seamed by extrusion welding processes, producing homogeneous seams. Seams are stronger than the original sheet due to increased thickness. High density polyethylene has lower resistance to puncture by rocks than many other liners of the same thickness; therefore, removal of rocks in the subgrade or use of geotextiles is important unless thicker membranes are used. Although this material has very large elongation, up to 500\%, it yields at low elongations, so very thin portions are created with elongations greater than $10 \%$. This material also has a higher coefficient of thermal expansion than other liners and is prone to bulge or grow where exposed to the hot sun. In the U.S. uranium industry, high density polyethylene is used at one holding pond.

There are alloys of high density polyethylene and unspecified materials on the market. These alloys are more flexible than high density polyethylene, while reportedly maintaining the other positive properties of high density polyethylene. They contain antioxidants, heat stabilizers, ultraviolet inhibitors, and carbon black. A high density polyethylene alloy is used for one uranium tailings pond in the U.S.

Low density polyethylene is a material that was once comonly used for linings because of its low cost. However, since it has poor weathering characteristics and poor resistance to puncture, its use as a liner has essentially been discontinued.

Polyvinyl chloride is perhaps the most popular material for lined impoundments in the country. In the U.S. uranium industry, it is used for tailings and evaporation ponds at three mills. Available in supported and unsupported 
forms, polyvinyl chloride has excellent puncture resistance and reported good chemical resistance to constituents in uranium tailings leachate. However, its resistance to ultraviolet rays is poor, so it should always be covered with soil. This material contains plasticizers, which are sometimes considered a detriment because plasticizers, especially low grade ones, tend to diffuse from the liner, leaving the membrane brittle and cracked. Some plasticizers are also prone to attack by both microbes and rodents. Polyvinyl chloride is also prone to shrinkage.

Chlorosulfonated polyethylene is another popular lining. It is available in supported forms of $0.91 \mathrm{~mm}$ and thicker. A nylon or polyester scrim provides superior tensile strength at the expense of elongation. It is available in $1.5-m$ wide sheets that are seamed at the factory, usually by dielectric heating. A bodied solvent is used for field seaming. Chlorosulfonated polyethylene has reportedly good chemical resistance except with certain hydrocarbons. We are aware of deterioration by kerosene of a chlorosulfonated polyethylene liner at a uranium mill. At least seven U.S. uranium mills use chlorosulfonated polyethylene for tailings and evaporation ponds. With a carbon black additive, it has excellent resistance to ultraviolet radiation. Although initially similar to a plastic, chlorosulfonated polyethylene slowly vulcanizes to an elastomeric material. Therefore, the recommended procedure is to store this material out of sunlight and in a relatively cool environment to prevent vulcanization prior to installation.

Chlorinated polyethylene is a flexible material created by chlorination (up to $30 \mathrm{wt}$ ) of polyethylene: It contains no plasticizers and is generally used in a $0.91-\mathrm{mm}$ reinforced form. Seaming techniques are similar to chlorosulfonated polyethylene. It also resists weathering. Chlorinated polyethylene is used at several evaporation ponds at one U.S. uranium operation.

Butyl rubber, ethylene-propylene-diene monomer, and ethylene-propyleneterpolymer are elastomeric liners that are available in both reinforced and nonreinforced forms and in thicknesses from 0.5 to $3 \mathrm{~mm}$. The nonreinforced forms have excellent elongation properties. Butyl rubber is slightly more prone to ozone damage than the other two materials, but all resist weathering. Resistance to uranium mill leachate components appears to be good, 
whereas hydrocarbon resistance is poor. These materials are relatively difficult to field seam. We know of no tailings or evaporation ponds in the uranium milling industry using these materials.

Neoprene (polychloroprene) is another elastomer with no current applications in the uranium milling industry. Neoprene ages poorly and costs more than the butyl-type rubbers.

Several other elastomers are on the market today. Epichlorohydrin rubber and spray-on urethane rubbers are available. We have not collected much information on these two materials.

\section{SEAM CHARACTER ISTICS}

When a designer is deciding what material to use for an impoundment, the seam properties for the material should be an important consideration. Also, the quantity of factory and field seams required should be addressed. In Table 4, we have compiled this information for the most common liner materials.

Seam techniques include dielectric, thermal, solvent, bodied solvent, gum tape adhesive, and extrusion welding. Dielectric seaming is the most complicated and is practiced only in the factory. Thermal methods are similar to dielectric seams and require close control of temperature and contact time. Solvent and bodied solvent systems are practiced in the field with polyvinyl chloride, chlorinated polyethylene, and chlorosulfonated polyethylene. Gum tape and adhesives are used with the elastomeric liners. Extruded welds are used for field seaming of high density polyethylene. Examples of seams are shown in Figure 1.

\section{CONFORMANCE TO ANOMALIES}

Material selection should also be based on the ability of materials to conform to expected anomalous features in the impoundment. These anomalies have been identified, as well as the important physical properties of liners. The response of liners when stressed over rocks is addressed in the final section of this report. 
IABLE 4. Typical Seam Characteristics of Various Geomembranes

\begin{tabular}{|c|c|c|c|c|}
\hline Material & Field Seam & Factory Seam & $\begin{array}{l}\text { Maximum } \\
\text { Unseamed } \\
\text { Sheet } \\
\text { Width, m } \\
\end{array}$ & $\begin{array}{l}\text { Typical } \\
\text { Factory } \\
\text { Sheet } \\
\text { Width, m }\end{array}$ \\
\hline HDPE (a) & $\begin{array}{l}\text { Extrusion weld } \\
\text { Fillet weld }\end{array}$ & None & $6-10$ & $6-10$ \\
\hline $\operatorname{CSPE}(b)$ & $\begin{array}{l}\text { Solvent bodied } \\
\text { adhesive }\end{array}$ & $\begin{array}{l}\text { Dielectric } \\
\text { Thermal } \\
\text { Bodied solvent }\end{array}$ & 1.5 & 21 \\
\hline $\mathrm{CPE}(\mathrm{c})$ & $\begin{array}{l}\text { Solvent bodied } \\
\text { adhesive }\end{array}$ & $\begin{array}{l}\text { Dielectric } \\
\text { Thermal } \\
\text { Solvent }\end{array}$ & 1.5 & 21 \\
\hline $\operatorname{PVC}(d)$ & $\begin{array}{l}\text { Solvent bodied } \\
\text { adhesive }\end{array}$ & $\begin{array}{l}\text { Dielectric } \\
\text { Thermal } \\
\text { Bodied solvent }\end{array}$ & 1.5 & 21 \\
\hline $\begin{array}{l}\operatorname{EPDM}(\mathrm{e}) \\
\text { EPT } \\
\text { Butyl, } \\
\text { Neoprene }\end{array}$ & $\begin{array}{l}\text { Gum adhesive } \\
\text { Contact adhesive }\end{array}$ & Vulcanized & 1.5 & 21 \\
\hline
\end{tabular}

a) High density polyethylene.

b) Chilorosulfonated polyethylene.

c) Chlorinated polyethylene.

d) Polyvinyl chloride.

e) Ethylene propylene diene monomer.

f) Ethylene propylene terpolymer.

Anomalies that may be present at uranium tailings ponds include rocks in subgrades, drainage pipes, other structures, and folds. In addition, localized subsidences and differential settlements may stress the liner. The material chosen for an impoundment should have mechanical properties which are suitable for the conditions that are expected. For some of these anomalies, we have listed in Table 5 the physical properties of the liner that are the most important in resisting failure. The use of geotextiles under and above a liner to reduce the probability of failures by most anomalies has been documented (Giroud 1982; Collins and Newkirk 1982). 


\section{LAP SEAM}

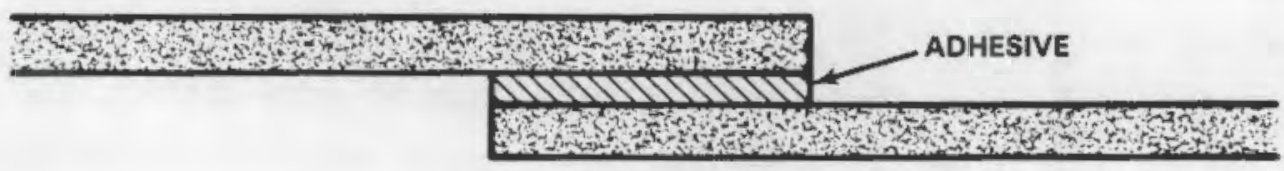

LAP SEAM WITH GUM TAPE

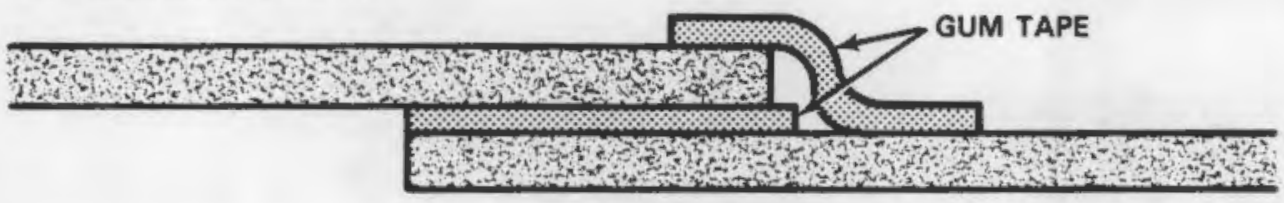

TONGUE AND GROOVE SPLICE

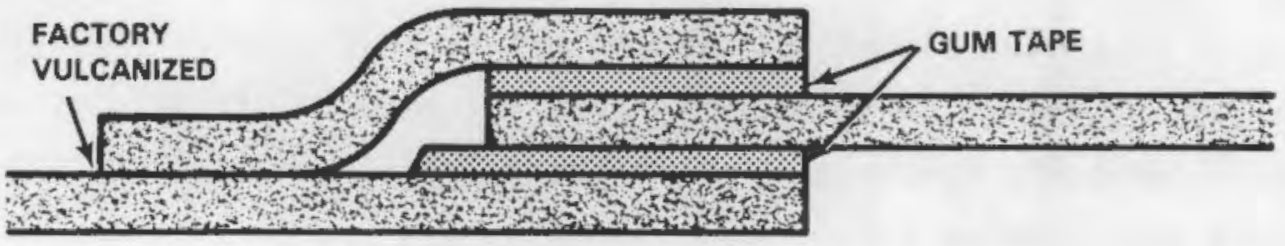

\section{EXTRUSION WELD LAP SEAM}

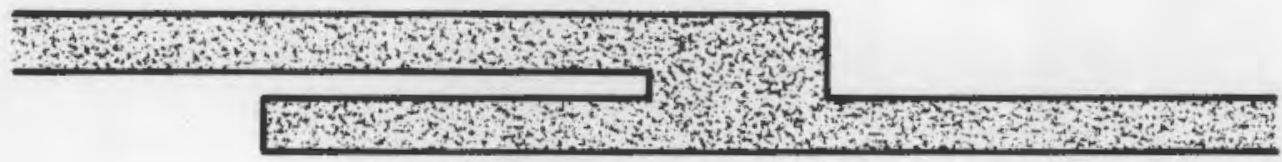

\section{FILLET WELD LAP SEAM}

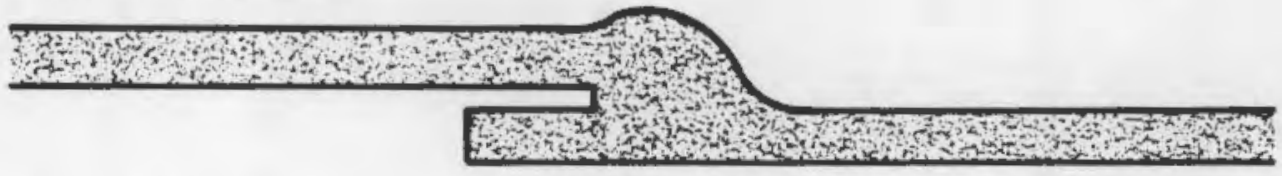

FIGURE 1. Typical Configurations of Geomembrane Field Seams

TABLE 5. Liner Properties that are Important for Resisting Failure Due to Stresses Created by Subgrade Anomalies

Anomaly

Rocks

Differential settlement

Subsidences

Pipes, structures
Important Liner Property

Puncture resistance

Elongation

Elongation

Tensile strength 
It has sometimes been suggested that folds or wrinkles in a liner reduce problems associated with shrinkage or subsidences. Folds or wrinkles do not appear to damage the liner, but they may make seaming more difficult. Due to the large forces on a liner in a filled impoundment, wrinkles or folds will not appreciably reduce the stresses created by subsidence unless the subsidence occurs directly below a fold.

\section{EFFECTS OF LINER STORAGE}

Improper storage, transportation, and handling of the geomembrane have been discussed earlier in this paper as factors that may contribute to failure of a lined impoundment. Some handling and storage procedures recommended by manufacturers have been collected. Two materials that require special storage procedures are polyvinyl chloride, which can suffer from ultraviolet damage, and chlorosulfonated polyethylene, which vulcanizes in heat, producing a film incompatible with seaming solvents (Williams 1982). 
IMPOUNOMENT DESIGN AND INSTALLATION PRACTICES

Pacific Northwest Laboratory has collected information on impoundment design and installation procedures practiced by industry, particularly the uranium milling industry. Areas addressed in this section include soil type, gradation, compaction, tolerances, soll sterilization, liner vent systems, leak detection systems, and liner protection systems.

SOIL TYPE, GRADATION, AND COMPACTION

Subgrade preparation procedures investigated at seven sites are listed in Table 6. The soil used in the subgrade is primarily dictated by the site, leak detection system requirements, and native soils in the area. Either a sand or a geotextile that can conduct gases is required under the liner. Compaction of the base to greater than $90 \%$ of the maximum dry density is the general practice. A grading tolerance of $\pm 0.03 \mathrm{~m}$ is recommended by Small (1980).

SOIL STERILIZATION

Soil sterilization is frequently practiced prior to installation of the liner to prevent germination of seeds in the soil and subsequent liner damage. This practice should be continued and procedures should be followed according to the sterilant manufacturer's recommendations.

Organic matter in the soil may decay and produce gases under the liner. For this and other previously discussed reasons, a liner vent system is necessary. The removal of soils with high organic content is desirable. Removal of root systems and surface plants is mandatory.

LINER VENT SYSTEMS

Liner vent systems are required for releasing gases trapped beneath liners in evaporation ponds, as previously discussed in the section on failure mechanisms. They are not as critical at tailings ponds where the force of tailings will prevent gas uplift. However, proper venting can eliminate problems we observed at one tailings pond, where trapped gases caused the uncovered liner 
TABLE 6. Subgrade Preparation Procedures Practiced at Some Uranium Mills

Site

1

(evaporation)

2

(evaporation)

3

(evaporation)

4

(evaporation)

5

(tailings)

6

(tailings)

7

(tailings)
Procedures

Remove $0.3 \mathrm{~m}$ of topsoil from site; grade to tolerance of $\pm 0.03 \mathrm{~m}$; test subgrade permeability; install drain network; cover with pea gravel.

Scarify 0.3 m of natural soi 1 ; recompact to $100 \%$ standard Procter density placed within optimum to $+2 \%$ moisture content; measure permeability; install drain network; install $0.15 \mathrm{~m}$ coarse sand.

Grade slope at $2.5 \%$ to center low1ine; compact to $90 \%$ of maximum dry density at optimum moisture; sterilize soil; scarify and reroll; install geotextile.

Excavate; remove roots, brush, loose earth, and rocks; scarify $0.15 \mathrm{~m}$; bring to optimum moisture; compact to $95 \%$ maximum dry density.

Excavate to approximate grade; trench for leak detection drains; inspect for open cracks and seal with grout; install drains; place clay in $0.15-m$ lifts; compact.

Excavate pond; add sand where needed; sterilize sand where needed; sterilize surface; roll surface.

Clear vegetation; remove soil with organic constituents; compact to $95 \%$ of maximum dry density.

slopes to bulge. At another uranium mill, "whates" or gas uplifts on a covered evaporation pond have occurred due to improper venting.

Two successful liner vent systems have been demonstrated at uranium mills. Baldwin (1983) describes a vent system using a geotextile under the liner. At this site the geotextile was an economical alternative to placement of a pervious sand layer. Sand layers and pipe drains have been used successfully at several evaporation ponds. Sand layers are generally $0.15-m$ deep. Sand layers and geotextiles also provide a smooth surface that should protect liners from puncture on the bottom side. Problems associated with sand layers include loss of sand by wind prior to liner installation and potential erosion of sand (piping) in the subgrade. Kays (1977) recommends a 3\% subgrade slope where gas evolution is expected. Vents should be placed at $15-m$ intervals just 
below the crest of the embankment. Thick plastic nets that transmit gases are an alternative to pipes for gas venting.

\section{LEAK DETECTION}

Leak detection systems used at uranium mill ponds consist of groundwater monitoring wells, lysimeter wells, drain systems, and combinations of these three systems. The drain system (if required) adds to the subgrade requirements of a pond.

The most recently constructed lined uranium mill ponds use a drain system which requires a base soil with a permeability two orders of magnitude lower than the soil directly below the liner. At many sites the compacted native soil meets these requirements. Perforated polyvinyl chloride pipes (2.5-cm to 15-cm dia.), all draining to a common sump, are placed at $12-m$ intervals in a 15-cm permeable sand or gravel layer directly below the liner.

Test data from this type of leak detection system have been reviewed by PNL. The systems will collect a small fraction of fluid, thereby indicating a leak. For construction of this type of system, a subgrade slope between 2 and $4 \%$ is recommended. This type of drain system will also vent gases and relieve any liquid underpressure created by groundwater. Additional work on novel leak detection systems was performed during this program, and results are reported by Myers et a1. (1983).

\section{SOIL COVERS FOR LINERS}

Functions of liner covers include protection from ultraviolet radiation, wind uplift, gas uplift, wave damage, foot traffic, ice damage, animal traffic, vandalism, and floating debris. Haxo (1980) states that a cover may reduce the rate of chemical degradation of a liner by reducing available surface area and providing a diffusion zone for reactants to penetrate.

Some problems associated with soil covers for synthetic liners include sloughing of the liner cover and puncture during placement. Of course, one disadvantage of liner covers is the additional cost that is incurred during 
installation. At an evaporation pond (with no tailings), location and repair of leaks are more feasible if there is no soil cover.

Two uranium mills have experienced sloughing of their covers; however, no liner damage due to sloughing has been reported. The construction characteristics of these covers are listed in Table 7. The sloughing that has occurred is attributed, respectively, to a rapid snow melt and very heavy precipitation that resulted in saturation of the cover material.

To prevent puncture of the liner, the soil cover must be free of large rocks and sharp particles. Cover materials should be screened to remove large particles. A geotextile can be placed over the liner prior to installation of an earth cover to reduce puncture potential.

From the data collected on liner covers, the following conclusions are made:

1. For evaporation ponds, liner soil covers are not desirable from a leak location and repair standpoint.

2. For polyvinyl chloride liners, soil covers are necessary because polyvinyl chloride is not resistant to ultraviolet radiation. For other liner materials, the designer will have to rely on manufacturer's data on ultraviolet resistance to determine the necessity of covers for ultraviolet radiation protection.

3. If no soil cover is used, wave damage to the embankment is possible.

4. If a soil cover is used, cohesive cover materials are recommended to minimize wind and water erosion and sloughing potential.

TABLE 7. Characteristics of Soil Covers at Lined Uranium Tailings Ponds

\begin{tabular}{|c|c|c|c|c|}
\hline Liner & Type of Soil & Depth, rl & Slope (v:h) & Stoughing \\
\hline HDPE alloy & Sand + cohesive spray & $0.3-0.6$ & $1: 3$ & yes \\
\hline CSPE & Clay-silt & 0.3 & $1: 3$ & yes \\
\hline CSPE & Sand + cohesive spray & $0.3-0.46$ & $1: 2.5$ & no \\
\hline PVC & Clay-silt & 0.6 & $1: 3$ & no \\
\hline
\end{tabular}


5. Weather is a factor in the design of covers. Where there is a possibility of water saturation of the exposed cover material, conservative choices of the cover material and the slope are required. Cohesive sprays may be warranted.

6. If a pond is built without a cover, the importance of other design and operation parameters increases. Some of these are prevention of animal trespass, removal of floating debris, gas venting, and prevention of vandalism.

7. A maximum slope of 1 vertical to 3 horizontal should be used on ponds with covers (Haxo 1980; Small 1980).

Other guidelines for soil covers concern actual installation procedures. Watersaver (1982) recommends $1-m$ deep access roads into the pond for heavy equipment. Bulldozers should always operate on layers at least 0.3-m thick. Sharp turns by haulers and dozers should be avoided because of the potential of rupturing or pinching the liner. Materials should be pushed up a slope starting at the bottom of the pond. Heavy equipment should not be operated on wet cover materials.

The use of heavy equipment on liners or covered liners is controversial. To reduce the puncture potential, weight limits of the equipment can be imposed and tracked vehicles or vehicles with large tires can be used. Again, geotextiles on the top and under the liner will reduce risk of puncture (Collins and Newkirk 1982).

Sma11 (1980) states that a $0.45-m$ thick soil layer should always be used and soil moisture should be at or below optimum moisture content to promote compaction. Some mills, however, have used covers only $0.3-\mathrm{m}$ deep (see Table 7). 
.

.

.

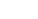




\section{NONDESTRUCTIVE INSPECTION TECHNIQUES FOR SYNTHETIC LINER SEAMS}

Because faulty seams are a frequent mechanism for failure of lined ponds, improved inspection of seams is one of the most productive leak avoidance measured. In this section, techniques presently used for seam inspection at field installations are evaluated and results of a testing program on several novel techniques are presented.

RESULTS

Several nondestructive testing techniques previously avajlable are adequate for finding unbonded areas of seams if an unbond is along the top edge of a seam or if it extends across a seam, forming a leak. These techniques (air lance, vacuum chamber, and pick test) will work on any liner material encountered in this research including both nonreinforced and reinforced materials. The pick test is quickest and requires the least operator skill, while the other two are more difficult but yield better information regarding the extent of an unbond. It is important to note that none of these three techniques is capable of detecting an unbond contained wholly within a seam, or even one that is along the edge of the bottom side of a seam.

Conventional pulse-echo ultrasonic testing is currently used to assure seam quality by one installer of lap-welded, high density polyethylene geomembranes. Our research shows that ultrasonic testing can be used to inspect any of the nonreinforced liner materials we examined except for fillet-welded, high density polyethylene. Equipment costs for the pulse-echo technique are significantly higher than the three previously described methods, and the operator skill required is comparable to the vacuum chamber test.

The most significant result of this work is discovering that the ultrasonic impedance plane technique can be used to find unbonds in seams made from almost all of the materials investigated. This technique is unique among acoustic methods in that unbond detectibility is not degraded by the scrim in reinforced materials. The ultrasonic impedance plane instrument is capable of detecting unbonds as small as $6 \mathrm{~mm}$ in diameter regardless of location in the seam. During a field demonstration, most of the seams with detected flaws were 
cut from the material for destructive analysis. These pieces all showed either voids or greatly reduced peel strength in the areas detected by the ultrasonic impedance plane instrument. When properly calibrated, this instrument requires less operator skill than pulse-echo ultrasonic testing and is slightly faster. On 76 mm-wide seams, our inspection rate reached 1 m of seam per minute using a 10 min-dia transducer mounted in our transducer holder. The equipment we used for this technique is even more expensive than the pulse-echo equipment. Even though we found many seam flaws during the field demonstration, very few would have been considered of rejectable size according to acceptance criteria followed by most liner installers. However, due to the frequency of seam failures, acceptance criteria may need to be increased to reduce the occurrence of this type of failure.

\section{SEAM SAMPLES}

During the laboratory phase of this research, four types of liner material were studied: polyvinyl chloride, high density polyethylene, chlorinated polyethylene, and chlorosulfonated polyethylene. Of these four materials, the chlorinated polyethylene and chlorosulfonated polyethylene were reinforced with loosely woven polyester scrim. Thickness of the materials was between 0.76 and $0.91 \mathrm{~mm}$ except for some of the high density polyethylene, which was $1.5-\mathrm{mm}$ thick.

Among commercial liner installers, seam acceptability is determined by the minimum well-bonded width at any point along a seam's length. For reinforced materials (chlorinated polyethylene and chlorosulfonated polyethylene), the minimum acceptable bond width for field seams is typically $4.1 \mathrm{~cm}$ at all points along a seam. The seams are usually made with $7.6 \mathrm{~cm}$ of overlap, so any unbond or combination of unbonds is acceptable as long as the unbonded dimension perpendicular to the seam length is less than about $3.5 \mathrm{~cm}$. For nonreinforced, adhesive-bonded materials such as polyvinyl chloride, the minimum acceptable bond width must be $5 \mathrm{~cm}$. Many installers overlap polyvinyl chloride by $10 \mathrm{~cm}$ to result in a nominal safety factor of 2 . One installer of high density polyethylene considers $1 \mathrm{~cm}$ the minimum bond width for thermally welded seams. In 
actual field seams, the most likely causes of unbonds are areas without sufficient adhesive, dirt inclusions, incorrect bonding temperature, and bubbles caused by trapped gases.

Seam samples, each about $0.5-\mathrm{m}$ long, were prepared by a commercial liner installer using that installer's appropriate field seaming procedure for each type of material. Some of the seams were made with no intentional defects (unbonds), but most of them were intentionally flawed. The defect types included sand, moisture, lack of glue, and masking tape. The masking tape was used to make carefully sized defects of from 3.8- to $0.95-\mathrm{cm}$ dia spots and 0.63- and $0.34-\mathrm{cm}$ wide strips. (Figures D.1 through D.3 in Appendix D show sketches of the glued seam samples and their defects.) All seams were nominally 7.6-cm wide. High density polyethylene is welded rather than glued in field installations, so some samples of two types of field welds were procured from high density polyethylene installers for this research. The two weld types were lap welds and fillet welds, and some of these also included intentional defects such as moisture, sand, and poor welding technique.

During the field demonstration phase of this research program, we had the opportunity to perform tests on many seam and material types in addition to the four tested during the laboratory phase. The field demonstration was carried out in cooperation with a U.S. Bureau of Reclamation (USBR) research project sponsored by the U.S. Environmental Protection Agency's Municipal Environmental Research Laboratory. The USBR research program involved 21 field seams and 16 factory seams made of various polymer materials supplied by 12 manufacturers. We tested 15 seams including ones made from polyvinyl chloride, reinforced and nonreinforced chlorinated polyethylene, chlorosulfonated polyethylene $(6 \times 6,1000-d$ and $10 \times 10,1000-d$ scrims), polyolefin, and high density polyethylene. Each seam was about $24-\mathrm{m} 1$ ong, but we tested about $3 \mathrm{~m}$ of each. Many of the field seams were also evaluated destructively to obtain correlations with the nondestructive examinations.

\section{TECHNIQUES INVESTIGATED}

One of the objectives of this research was to investigate various seam quality inspection techniques in an attempt to find one that would work best on 
the greatest number of materials, seam types, and defect types. Some of the techniques investigated are currently in use by geomembrane installers, while others have never been applied as field inspection techniques. In the course of this research, about 15 different inspection techniques were studied. The more significant techniques are listed below, with a general description and qualitative assessment of the usefulness of each. Unless otherwise stated, each of these techniques works on all liner types investigated.

Visual--This technique is used to some degree by all installers. Large bubbles and fish mouths can readily be found by this method.

Air Lance--This technique effectively determines how far across the seam an unbond extends. A jet of air is blown at the edge of the top piece on a seam. Any openings along the edge become inflated and easily visible. The air lance requires a careful operator to detect unbonds, and works only if the defect is open on the top surface of a seam (see Figure 2).

Pick Test--This method detects the same defect types as an air lance, but requires less operator skill. To look for unbonds, a dull object (such as a nail with the sharp point ground off) is slid along the edge of the top piece

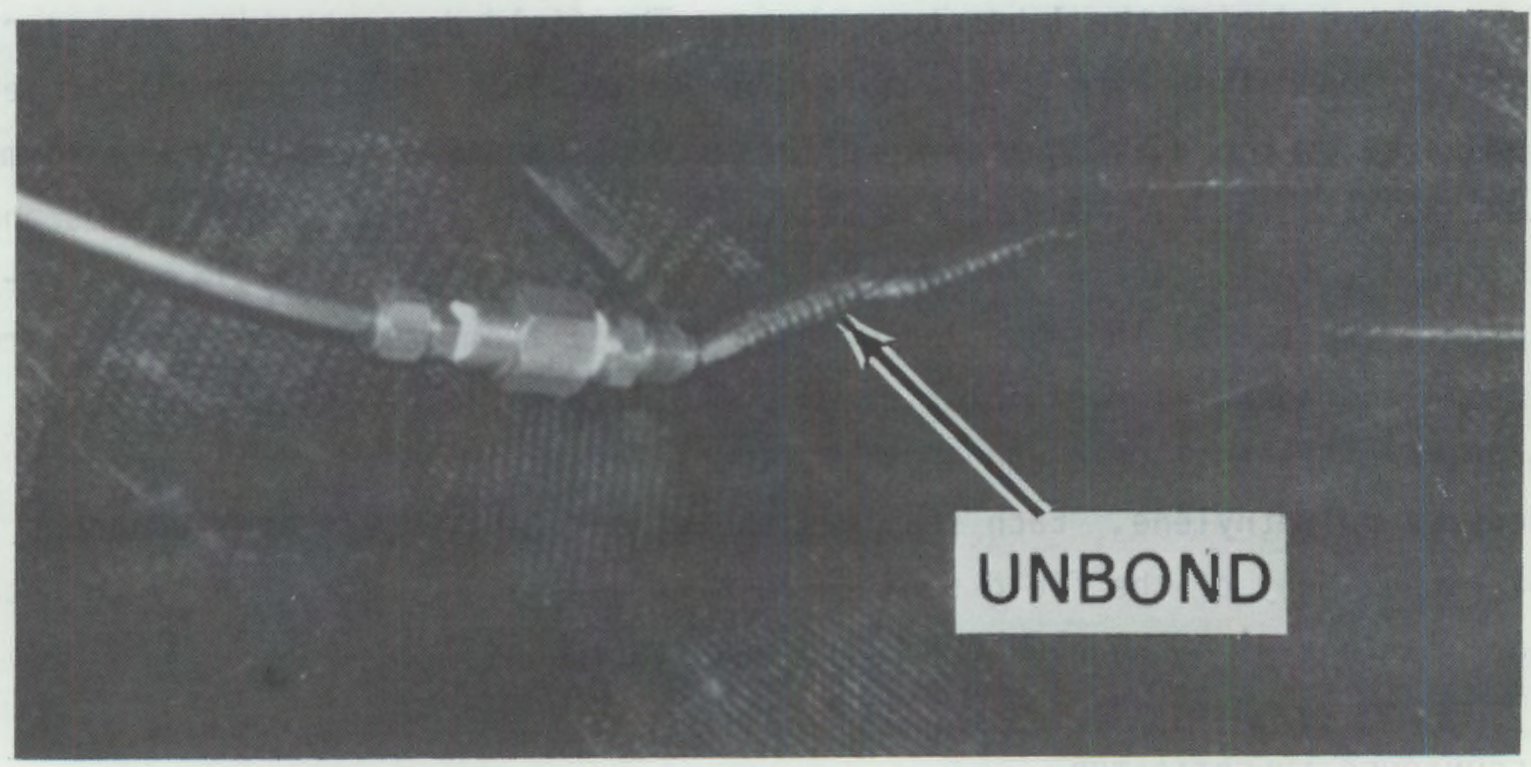

FIGURE 2. Air Lance Detecting an Unbond in a Chlorosulfonated Polyethylene Seam 
on a seam. Wherever an open unbond exists, the pick digs into the opening. Detectibility is equal to the air lance, but the pick test does not determine the size of unbonds.

Vacuum Chamber--In the vacuum test, a $1-m$ long gasketed chamber is placed over a section of seam that has been coated with liquid soap. The chamber, which has a transparent top, is then partially evacuated using an air pump. Any unbonds that extend across the seam are then indicated by the presence of soap bubbles. This test is very sensitive to small leaks, and has the additional feature of stressing the seam to cause marginally bonded areas to become unbonded, thereby indicating a leak (see Figure 3 ).

Sample Destructive Tests--At regular intervals during installation, seam samples are made up or cut out and then destructively examined, usually by peel

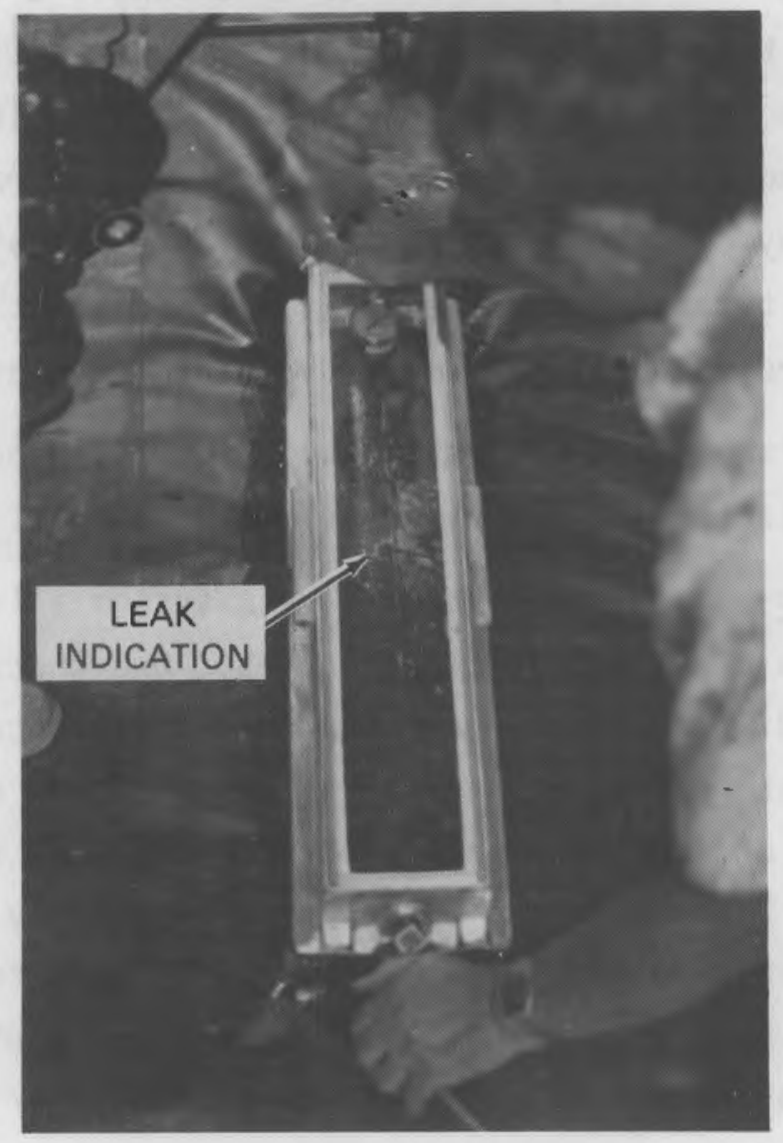

FIGURE 3. Vacuum Chamber Detecting a Leak in a Chlorosulfonated Polyethylene 
testing. This method is useful for detecting gross problems in the seaming process, such as defective glue, incorrect bonding temperature, etc.

Monitor Welding Parameters--For seams that are thermally joined or extrusion welded, certain key parameters need to be controlled to permit a good bond to form. These parameters may include extrudate temperature, hot air temperature, seaming rate, sheet temperature, and contact pressure. While the control of welding parameters cannot guarantee a good bond, this technique is useful because any violation of the parameters assures a poor bond.

Pulse-Echo Ultrasonics--This technique involves transmitting an ultrasonic pulse of energy into the seam and interpreting the returned echo on a timebased cathode ray tube. A well-bonded area would produce an echo later in time than an unbond because the ultrasound pulse would have traveled round trip through two sheet thicknesses, whereas at an unbonded area the echo returns after a round trip through only the top sheet thickness (see Figures $4 a$ and 4b). To assure good bonding throughout a seam, the entire surface area of the seam must be scanned with a transducer. Pulse-echo ultrasonic testing is currently being used by one high density polyethylene installer, and our research indicates that the technique works equally well on all the nonreinforced materials that we tested, such as polyvinyl chloride and elasticized polyolefin.

The following seam quality testing techniques are not currently employed by geomembrane installers, but were investigated as part of this research.

Infrared Video--An infrared video camera system allows the detection of seam areas that are at different temperatures. One characteristic that would cause temperature differences is heat transfer differences resulting from areas that are not intimately bonded. An infrared inspection would then consist of viewing the length of each seam while looking for areas that are cooler than most of the seam. This technique worked only marginally in the lab, and in the field too many effects besides bond quality would tend to mask the temperature differences caused by a poor bond. Two likely masking effects are moist areas under the liner and nonuniform contact between the liner and the substrate. This technique was field tested by the Bureau of Reclamation (Morrison et al. 1981) with similar results. 

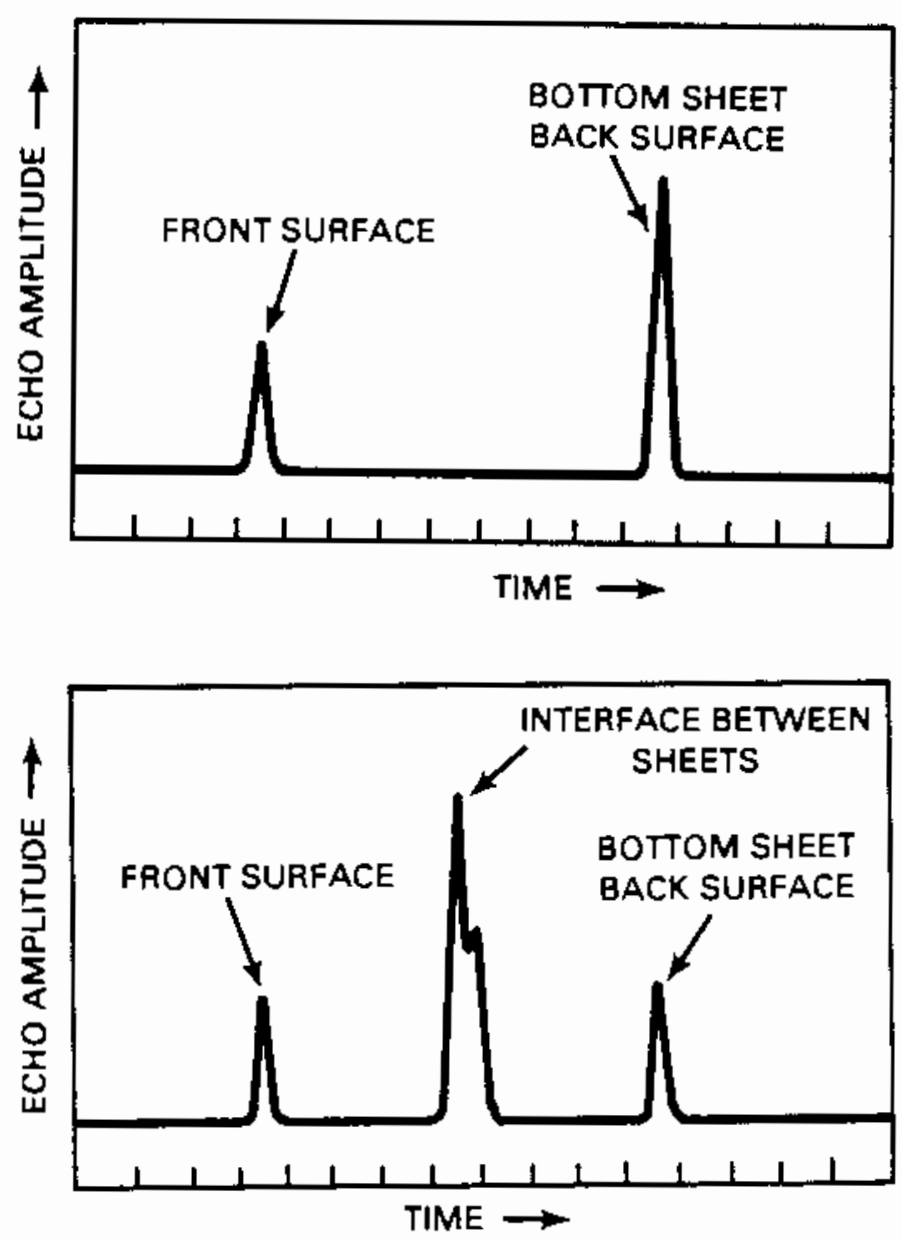

FIGURE 4. Sketches of a Typical Pulse-Echo Ultrasonic Screen Display for a) a Well-Bonded Seam and b) a Faulty Bond of Nonreinforced Material

Proprietary Acoustic Instruments--four different conmercial instruments using acoustic principles were tried on the seam samples. While each instrument was unique in some ways, they had several features in common. Each operated at relatively low frequency, less than $100 \mathrm{kHz}$. All of the instruments operated without a wet coupling medium between the transducer and the test piece. The instruments, designed for the aerospace industry, operate on a similar principle. They each apply acoustic energy to the area being tested and then present the reflected energy signal on a display screen or a meter. 
None of the four instruments was capable of determining with any consistency the quality of any of the sample seams.

Ultrasonic Resonance--In this technique, a tone-burst pulse of many cycles of ultrasonic energy is transmitted into a seam by a transducer. The length of the reflected pulse varies as the quality of the bond varies, allowing the operator to determine the quality of the bond in the area under the transducer. Ultrasonic resonance worked well on nonreinforced polyvinyl chloride but did not work on the reinforced materials. The technique is about as effective as pulse-echo ultrasonics, except that interpretation is somewhat more difficult.

Ultrasonic Impedance Plane Technique--This testing technique was found to work best on the broadest range of materials and is described in detail in the following section.

ULTRASONIC IMPEDANCE PLANE INSTRUMENT

The inspection technique that worked best on the most materials was the ultrasonic impedance plane technique. The principle behind this technique is that a well-bonded seam possesses a certain acoustic impedance and any other area that is not as well bonded possesses a different acoustic impedarice. The instrument used is capable of digitally "remembering" the characteristic impedance of the well-bonded area and of indicating visually whenever an unbonded area is detected. The primary readout on the instrument is the cathode ray tube screen, where a digital "flying dot" represents the tip of an acoustic impedance vector corresponding to the characteristic phase and amplitude of a test area's acoustic impedance. The other visual indications of bond integrity are a light-emitting diode alarm on a probe and a meter that can display either relative amplitude, phase, or the vertically resolved component of an impedance vector.

To use the ultrasonic impedance plane instrument, it must first be calibrated for the particular material and bond type to be inspected. The first step in calibration is to place the transducer (or probe) on a well-bonded area and adjust the display so that the dot displayed for a good bond is at the center of the screen. Next, the transducer is placed on an unbonded area and the dot address for unbonds is stored on the screen. Another dot is then likewise 
stored to represent when the transducer is not acoustically coupled to the piece under test. After the likely dot addresses are stored (up to eight), the display, alarm light, and meter can be adjusted to give the most convenient outputs. A useful modification of this procedure in the field was to squirt ultrasonic gel couplant between the liner layers to simulate a well-bonded area. Calibration was then carried out as described above while sliding the transducer between the bonded area and the unbonded area.

When inspecting a seam with this instrument, the operator scans the transducer over the seam area while watching transducer position and the probe alarm light. If a preset adjustable threshold is exceeded, the light glows, which alerts the operator to look at the screen. He can then determine from the displayed dot position what the condition of the bond is in the area beneath the probe. If the area is unbonded, the flying dot will be in the vicinity of the calibration dot corresponding to an unbond condition. If the probe is somehow not acoustically coupled to the test piece (lack of liquid couplant, rough surface, etc.), the flying dot will be in the vicinity of the stored dot corresponding to an uncoupled transducer. Watching the alarm light while moving the probe, the operator can mark the boundaries of the unbonded area with a grease pencil.

The probe used with this instrument is very similar to a conventional ultrasonic transducer, except that it operates at a lower frequency than most and has a built-in, alarm triggered, light-emitting diode. Several probes are available for the instrument, but we had access to only one for this research. The probe used was 95-mm diameter with a frequency range from 160 to $185 \mathrm{kHz}$. We operated it at about $167 \mathrm{kHz}$. A liquid couplant is required with this instrument to get the ultrasound energy through the specimen/transducer interface. We found tap water to be a good couplant and used it in our experiments.

\section{FIELD DEMONSTRATION}

The second phase of this research was demonstration of a nondestructive testing technique in the field on actual field seams. We originally planned to go to a field installation in progress, but we gained several advantages by 
participating in an EPA-sponsored research experiment that is being carried out by the USBR in Denver, Colorado. In the USBR project a commercial geomembrane installer was contracted to fabricate field seams on a variety of materials. One major advantage to participating in this experiment was that we were allowed to remove sections of the seams after nondestructive testing so that they could be destructively evaluated in the USBR laboratories. This helped greatly in establishing the validity of the techniques demonstrated. Another advantage was that we were able to compare the performance of six testing techniques on certain seams (air lance, vacuum, pick, visual, pulse-echo ultrasonics, and ultrasonic impedance plane analysis). The third benefit was the large assortment of materials that we were able to test, including field seams of the four materials that were considered in the laboratory phase of our research. Our testing was carried out on a loose sand floor over hard packed dirt inside an open metal building.

At the USBR laboratories we demonstrated a conventional pulse-echo ultrasonic unit and the instrument that operates on the ultrasonic impedance plane principle. The puise-echo instrument was a Krautkramer-Branson USL-38, while the ultrasonic impedance plane instrument was an NDT instruments Bondascope 2100. For these demonstrations, the pulse-echo frequency was between $5 \mathrm{MHz}$ and $15 \mathrm{MHz}$ and the ultrasonic impedance plane frequency was $167 \mathrm{kHz}$. Two types of couplant were used to help transmit ultrasonic energy into the materials: gel couplant for pulse-echo and tap water for ultrasonic impedance plane testing. The gel couplant was also used between two liner layers to simulate a good bond when calibrating the ultrasonic impedance plane instrument. The only modification we made to either instrument was to build a transducer holder for the uitrasonic impedance plane instrument. As shown in Figures 5 and 6, the holder is a transparent block that has a water supply line attached to it. A cavity around the transducer retains water so that adequate acoustic coupling is assured at all times. The holder allows observation of the alarm light and is more comfortable for the operator to hold, so it helped increase the ultrasonic impedance plane inspection rate while preventing false alarms from lack of couplant. 


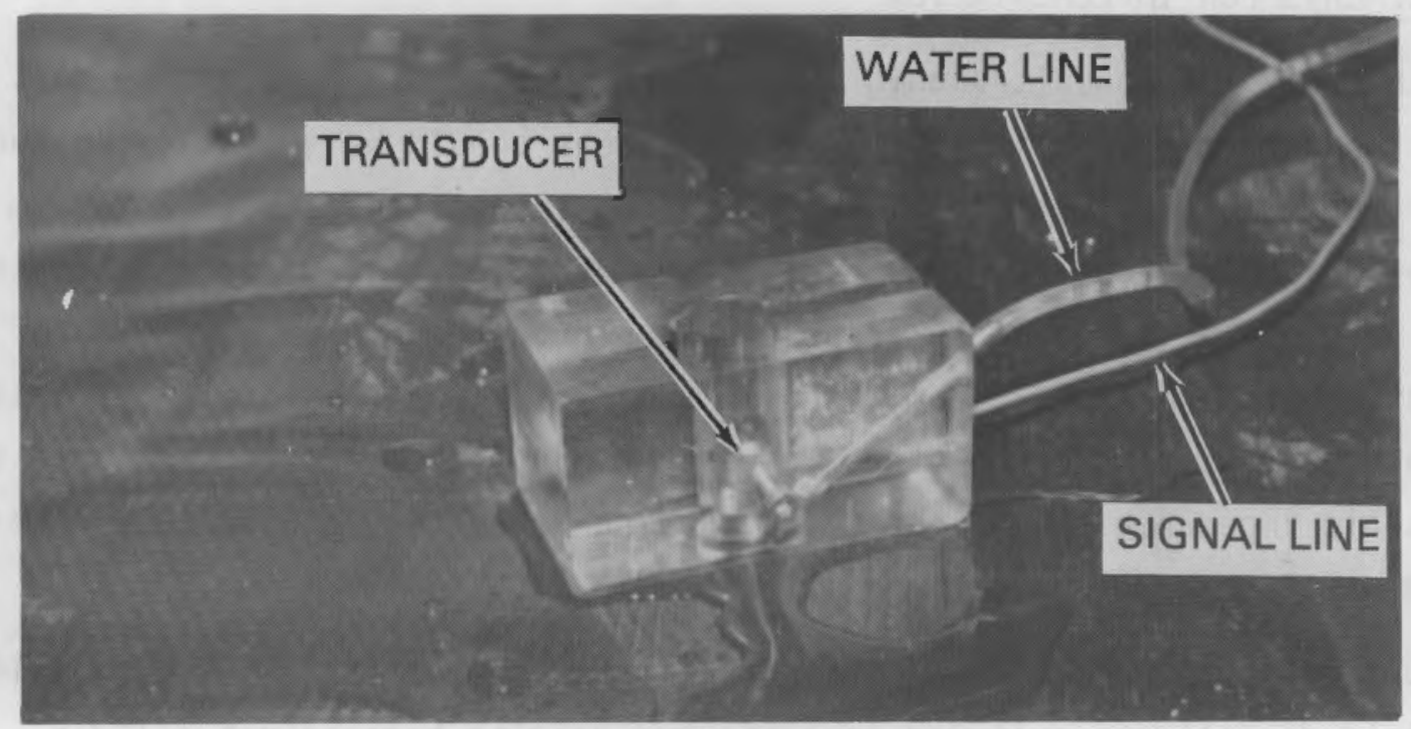

FIGURE 5. PNL-Designed Holder for the Ultrasonic Impedance Plane Instrument

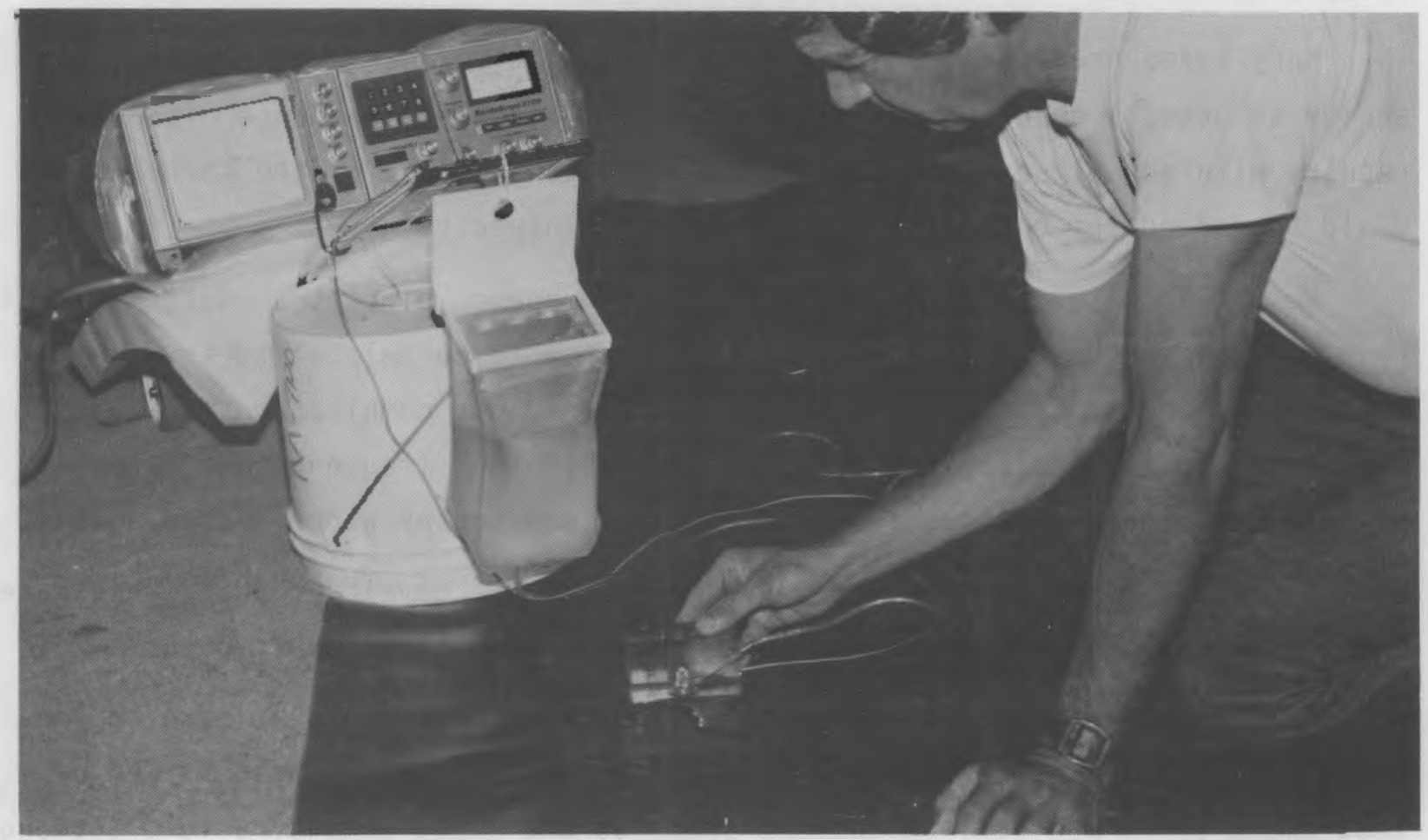

FIGURE 6. Seam Inspection Transducer Holder with the Ultrasonic Impedance Plane Instrument 
REQUIREMENTS FOR IMPLEMENTATION

In order for the ultrasonic impedance plane technique to become most useful for the geomembrane industry, several areas should be investigated further. Several installers mentioned a desired inspection rate of 2 to $3 \mathrm{~m}$ per minute, which is about twice as fast as was achieved at the field demonstration. A good way to speed up inspection would be to develop a transducer wide enough to test the entire seam width in one pass. The feasibility of this approach was established by other researchers that used a predecessor to the ultrasonic impedance plane instrument, having found that a wide transducer worked well for bond inspection.

Our calibration procedure was convenient; however, on a few materials at the field demonstration it led to ambiguous results because not all dot addresses encountered during inspection had been previously accounted for during calibration. Using carefully made seam samples with known defects like our laboratory control samples would be a likely place to start this work.

Many seams need to be tested both nondestructively and destructively to arrive at acceptance criteria that correlate ultrasonic impedance plane test results with actual seam peel or tensile strengths. Sets of the correlations would be needed for each liner material to be inspected.

We were limited to only one ultrasonic impedance plane transducer for this research, although several are available. It would be helpful to try the others in order to optimize the instrument/transducer combinations for each material. In particular, a transducer of a different frequency and diameter may eliminate the sometimes ambiguous results created by wider-spaced scrims.

To record inspection results, hardware could be developed that would make a hardcopy (such as a strip chart) of each seam inspection as it occurs.

Finally, the ultrasonic impedance plane instrument could be adapted for monitoring the quality of factory seams in the manufacturing plant. The instrument performed well on factory seams at the field demonstration, although an automated inspection would be desirable for process control. 
ACCELERATED AGING TESTS

The objective of these tests is to predict the long-term (20-year) performance of liner materials in a uranium tailings pond. This is being accomplished by aging liners under conditions typical of an actual tailings impoundment and by using elevated temperatures to accelerate degradation reactions. By measuring the chemical and physical changes in the liner we will try to develop a correlation between the amount of aging and the changes observed in physical properties.

This task is about half complete. High density polyethylene and polyvinyl chloride liners have been aged and are being examined. Chlorosulfonated polyethylene liners are presently being aged. Exposure of chlorinated polyethylene samples will conclude the aging studies. The following discussion includes aging analysis, experimental procedure, and results to date.

\section{AGING ANALYSIS}

Schnabel (1981) defines polymer degradation as changes in physical properties caused by reactions invorving bond scission. Degradation may be caused by chemical, photochemical, biological, thermal, mechanical, and radiation mechanisms. For geomembranes the first three mechanisms are of importance. Our study is examining long-term chemical degradation processes. In addition to polymer degradation, there may be reactions that crosslink the polymer, thereby changing physical properties. This possibility is also being investigated.

Chemical degradation mechanisms outlined by Schnabel (1981) include solvolysis (breaking of bonds between carbon and non-carbon atoms in the main chain in a liquid phase), metathesis (breaking of carbon-carbon double bonds), oxidation (direct one-step liquid reactions and autoxidation chain reactions with molecular oxygen), and dissolution mechanisms. All of these reactions may be important for liners in acidic uranium tailings ponds.

Carbonyl groups are the principal products of oxidation of polyethylene (Myers 1952). Differential infrared spectroscopy can be used to analyze for carbonyl formation in liners, as reported by Buelt and Barnes (1983). Infrared 
spectroscopy may be used to quantify end groups (Schnabel 1981). This technique will be important in analyzing oxidation reactions and scission products.

Molecular weight determinations may be used to quantify scission and crosslinking reactions, while differential scanning calorimetry can reveal changes in crystallinity.

The kinetics of aging reactions are analyzed by classical chemical methods. The liners are aged under identical conditions (pressure, leachate composition, $\mathrm{pH}$ ). The three columns (described in the next subsection) are operated at 18,48 , and $78^{\circ} \mathrm{C}$. The column at $18^{\circ} \mathrm{C}$ represents an average yearly temperature $15 \mathrm{~cm}$ below the soil, which would vary from site to site. The rates of reaction at each temperature are measured by chemical analysis. Because the other conditions of the columns are identical for any reaction observed, rate constants are directly determined from observed rates:

$$
K_{t}=R_{t} / C
$$

where $K_{t}$ is a rate constant at temperature $\left({ }^{\circ} \mathrm{C}\right), R_{t}$ is the measured rate at the same temperature, and $C$ is a constant. The rate constant is a function of temperature according to the Arrhenius equation (Perry 1969):

$$
K=A e^{-E / R T}
$$

where $A$ is a constant, $E$ is the reaction activation energy, $T$ is temperature $\left({ }^{\circ} \mathrm{K}\right)$, and $\mathrm{R}$ is the gas constant. A plot of the logarithm of the rate constant as a function of reciprocal temperature will yield a line with a slope equal to E/R. An example of such an analysis is reported by Myers (1952), who determined an activation energy for the oxidation of polyethylene in air equal to $16,000 \mathrm{cal} / \mathrm{g}-\mathrm{mole}$.

The activation energy is used to determine how much aging was simulated. Assuming that an activation energy of $16,000 \mathrm{cal} / \mathrm{g}-m o l e$ was determined in an 
experiment, the amount of aging at $78^{\circ} \mathrm{C}$ compared to non-accelerated exposure at $18^{\circ} \mathrm{C}$ is determined by calculating an aging factor equal to:

$$
\frac{r_{78}}{r_{18}}=e \frac{-E}{R} \quad \frac{1}{351}-\frac{1}{291}
$$

The aging factor multiplied by the length of exposure equals the amount of aging simulated. In the example, the aging factor is 113 , so in an 18 week exposure, the effects of 2040 weeks (39 years) of aging on physical properties would be simulated.

There are two potential limitations to this type of analysis. First, there is a possibility of multiple parallel reactions and the subsequent determination of several activation energies. Second, the diffusion of components such as plasticizers from the liner would not necessarily follow the Arrhenius equation, and therefore plasticizer effects may not correlate with the physical property changes observed.

Biggs (1953) states that diffusion of molecular oxygen limits reactions at depths greater than $5 \mathrm{~mm}$ for polyethylene. For this reason we analyze carbonyl formation as a function of depth in the liner. This is done by microtoming 25-micron layers of aged liner and examining the chemical changes in each layer. (The microtome procedure is discussed in Appendix A.)

\section{COLUMN DESCRIPTION}

Three test columns were assembled according to the schematic of figure 7 . The columns are made of $0.61-m\left(24-i n_{.}\right)$stainless steel pipe. The columns are heated or cooled by fluid circulating in copper coils around the column exterior. Insulation helps maintain the liner at the desired temperature across the diameter of the column. The column at $18^{\circ} \mathrm{C}$ is cooled by a heat pump. The other columns are heated by fluid circulating from heated drums.

A press on top of the column is used to load the sand above the liner. The simulated depth of tailings provides some stress that may affect aging. The loading on the press is checked weekly and is equivalent to $2.3 \mathrm{~m}(7.7 \mathrm{ft})$ of tailings. 


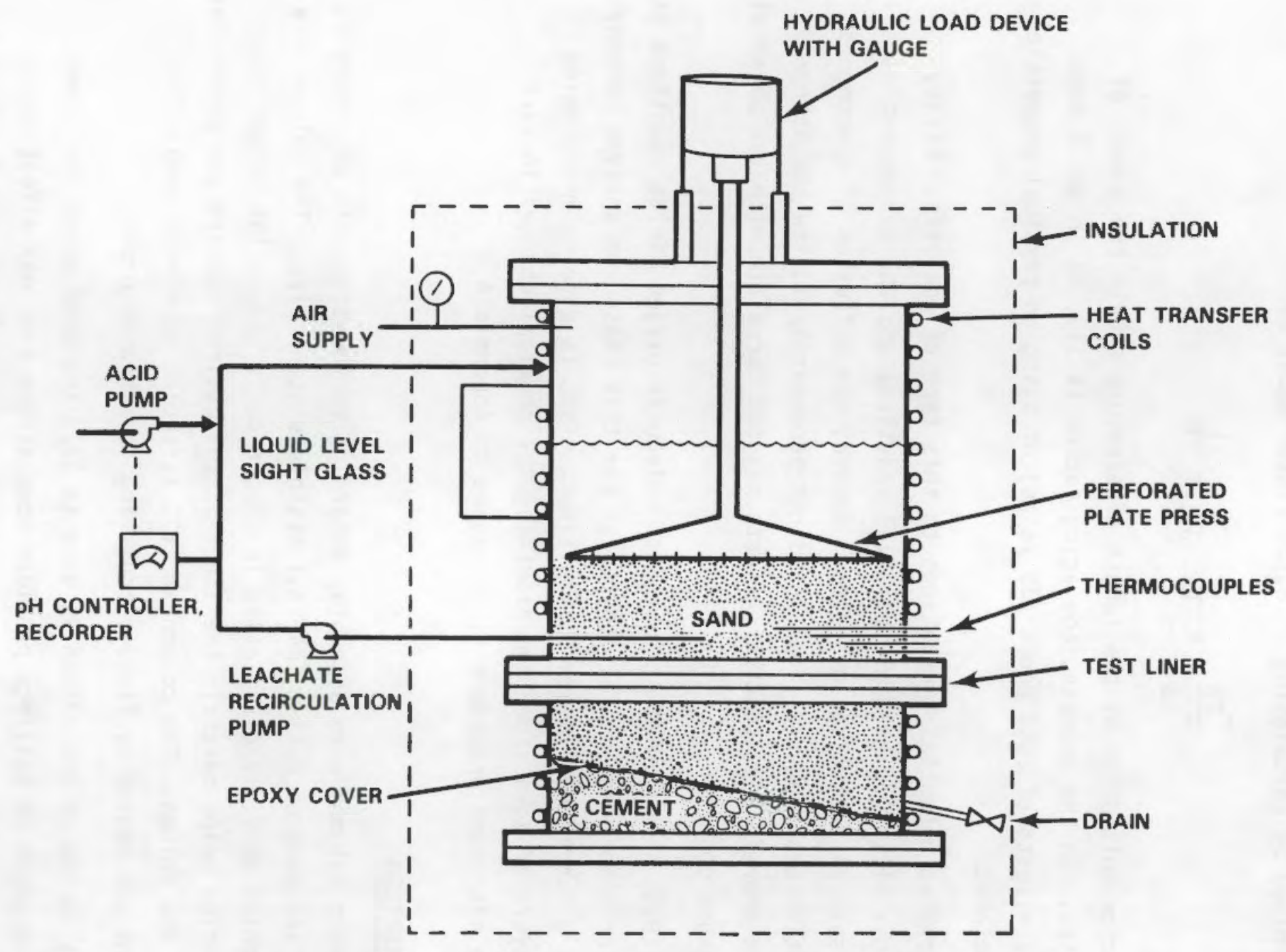

FIGURE 7. Schematic of Accelerated Aging Column 
Air pressure is maintained at $5 \mathrm{~kg} / \mathrm{cm}^{2}$ ( 8 to $9 \mathrm{psig}$ ), simulating a liquid head of $6 \mathrm{~m}(20 \mathrm{ft})$ of water. The column pressure is bled weekly and repressurized to keep the oxygen concentration at $21 \%$.

\section{EXPERIMENTAL PROCEDURE}

Liners with seams cut to fit in the test column are covered with a 25-cm layer of fine silica sand (particle size $<210 \mu \mathrm{m})$ to simulate tailings. Seventy liters of simulated leachate is added to the column. The leachate composition is given in Table 8. The columns are then sealed and slowly heated

\section{TABLE 8. Simulated Leachate Composition}

\section{Concentra-}

Component tion, ppm

$\mathrm{H}_{2} \mathrm{O}$

A1

As

$\mathrm{Ca}$

$\mathrm{Cl}$

Co

$\mathrm{Cr}$

Cu

$\mathrm{Fe}$

K

$\mathrm{Mg}$

Mn

Mo

$\mathrm{Na}$

$\mathrm{NH}_{3}$

$\mathrm{Ni}$

Se

Si

$\checkmark$

Zn
1000

3

500

300

1

3

5

2215

20

700

100

5

376

500

3

20

230

1

10
$\mathrm{H}_{2}$

$\mathrm{H}_{2} \mathrm{O}$

$\mathrm{Al}_{2} \mathrm{SO}_{4}$

$\mathrm{As}_{2} \mathrm{O}_{3}$

$\mathrm{CaCO}_{3} / \mathrm{CaCl}_{2} \cdot 2 \mathrm{H}_{2} \mathrm{O}$

see $\mathrm{Ca}$

$\mathrm{CoCl}_{2} \cdot 6 \mathrm{H}_{2} \mathrm{O}$

$\mathrm{CrO}_{3}$

$\mathrm{CuSO}_{4} \cdot 5 \mathrm{H}_{2} \mathrm{O}$

$\mathrm{FeSO}_{4} \cdot 7 \mathrm{H}_{2} \mathrm{O}$

$\mathrm{K}_{2} \mathrm{CO}_{3}$

$\mathrm{MgSO}_{4} \cdot 7 \mathrm{H}_{2} \mathrm{O}$

$\mathrm{MnSO}_{4} \cdot \mathrm{H}_{2} \mathrm{O}$

$\left(\mathrm{NH}_{4}\right) \mathrm{Mo}_{7} \mathrm{O}_{24} \cdot 4 \mathrm{H}_{2} \mathrm{O}$

see $\mathrm{Si}$

$\left(\mathrm{NH}_{4}\right)_{2} \mathrm{SO}_{4}$

139

$\mathrm{H}_{3} \mathrm{PO}_{4}$ (85\%)

8.5

$\mathrm{H}_{2} \mathrm{SeO}_{3}$

2.5

132.0

0.14

3.3

75,600

$63 / 46.5$

0.3

0.44

1.5

834

2.7

23

0.7

$\mathrm{Na}_{2} \mathrm{SiO}_{3} \cdot 5 \mathrm{H}_{2} \mathrm{O}$

$\mathrm{V}_{2} \mathrm{O}_{5}$

$\mathrm{ZnSO}_{4} \cdot 7 \mathrm{H}_{2} \mathrm{O}$ 
(over 2 days) to desired operating temperatures. The column presses are loaded and air pressure is applied to the column. After checking for leaks, the columns are insulated.

Columns are maintained at the designated temperature for 18 weeks. Normal operations include continuous temperature recording and daily monitoring of $\mathrm{pH}$, liquid level, and air pressure. The column presses are loaded weekly and locked into position. The leachate is circulated on weekdays for several hours each day, providing operators with $\mathrm{pH}$ data. If the $\mathrm{pH}$ rises above 2.5, operators add concentrated sulfuric acid to maintain the $\mathrm{pH}$ between 2.0 and 2.5 .

The columns are disassembled after 18 weeks at the specified temperatures. First, the tops of the columns are removed and the leachate is sampled and drained. Then the simulated tailings are removed from the vessel. Next the liner is removed, labeled, and rinsed. Liners are stored in plastic bags in the dark until ready for testing.

Samples are cut from the liner for physical and chemical tests. The cutting must be arranged so that seamed samples are available for tests of shear strength and anomaly conformance.

Samples are microtomed to a thickness of 25 microns for subsequent chemical analysis. These samples are handled with rubber gloves and tweezers and stored in an inert atmosphere in the dark to prevent any additional reactions. Physical Testing

We have used or plan to use the following tests in this project:

- seam strength (shear)

- tear strength

- ply adhesion (reinforced samples)

- elongation and tensile strength.

The procedures are modified ASTM (American Society for Testing Materials) methods in most cases, as recommended by the National Sanitation Foundation (see Appendix B for procedures). 


\section{Results}

The first series of chenical and physical tests to determine the effects of exposure were with high density polyethylene samples. The results of these tests are discussed here.

The daily conditions in the columns were monitored and plotted (see Appendix $($ ). The average conditions over the 18 week period of exposure are listed in Table 9. The leachates from the columns were sampled near the beginning and at the termination of the tests. The leachate composition varied slightly between the columns due to increased corrosion of the stainless steel as the temperature rose. Apparently 316 stainless steel, which is recommended for dilute sulfuric acid, is not totally compatible with the mixture of materials in the leachate. A Tefion lined column might prevent this problem.

The results of tests with the differential scanning calorimeter are shown in Table 10. The crystallinity appears to be a function of the temperature to which the liner was exposed. Billmeyer (1971) presents data indicating that polymer crystallization does not follow Arrhenius kinetics. Crystallization is a molecular reorganization, not a reaction. With increasing crystallinity we would expect an increase in mechanical properties.

The results of differential infrared spectroscopy in the carbonyl absorbing region are shown in Figure 8. These data show that changes in the carbonyl concentration in high density polyethylene are insignificant following an 18 week exposure in acidic leachate at all the temperatures tested. It appears that either oxidation rates are, extremely low for high density polyethylene in this environment, or oxidation products are being dissolved in the leachate.

JABLE 9. Average Exposure Conditions of High Density Polyethylene Samples

\begin{tabular}{ccccc} 
& \multicolumn{2}{c}{$\begin{array}{c}\text { Temperature, } \\
{ }^{\circ} \mathrm{C}\end{array}$} & & $\frac{\mathrm{pH}}{\text { Pressure, psig }}$ \\
\cline { 2 - 2 } Column 1 & 18 & & 2.22 & 8.29 \\
Column 2 & 48 & & 2.27 & 8.38 \\
Column 3 & 78 & & 2.34 & 8.35
\end{tabular}


TABLE 10. Results of Differential Scanning Calorimetry on Virgin and Aged High Density Polyethylene Samples

\begin{tabular}{|c|c|c|c|}
\hline Sample & Depth, $\mu m$ & $\Delta \mathrm{Hf}, \mathrm{Cal} / \mathrm{g}$ & Crystallinity, $\%$ \\
\hline \multirow[t]{4}{*}{ Virgin } & 18 & 35.51 & 51.9 \\
\hline & 36 & 35.61 & 52.1 \\
\hline & 51 & 35.69 & 52.2 \\
\hline & 77 & 36.14 & 52.8 \\
\hline \multirow[t]{4}{*}{$18^{\circ} \mathrm{C}$} & 33 & 34.39 & 50.3 \\
\hline & 51 & 35.24 & 51.5 \\
\hline & 74 & 35.96 & 52.6 \\
\hline & 97 & 35.29 & 51.6 \\
\hline \multirow[t]{7}{*}{$48^{\circ} \mathrm{C}$} & 18 & 36.4 & 53.2 \\
\hline & 36 & 36.49 & 53.3 \\
\hline & 53 & 36.31 & 53.1 \\
\hline & 71 & 36.57 & 53.5 \\
\hline & 89 & 36.88 & 53.9 \\
\hline & 107 & 36.23 & 53.0 \\
\hline & 127 & 37.00 & 54.1 \\
\hline \multirow[t]{8}{*}{$78^{\circ} \mathrm{C}$} & 20 & 37.87 & 55.4 \\
\hline & 41 & 39.00 & 57.0 \\
\hline & 58 & 39.19 & 57.3 \\
\hline & 76 & 39.14 & 57.2 \\
\hline & 23 & 37.18 & 54.4 \\
\hline & 38 & 36.99 & 54.1 \\
\hline & 53 & 37.74 & 55.2 \\
\hline & 74 & 37.60 & 55.0 \\
\hline
\end{tabular}




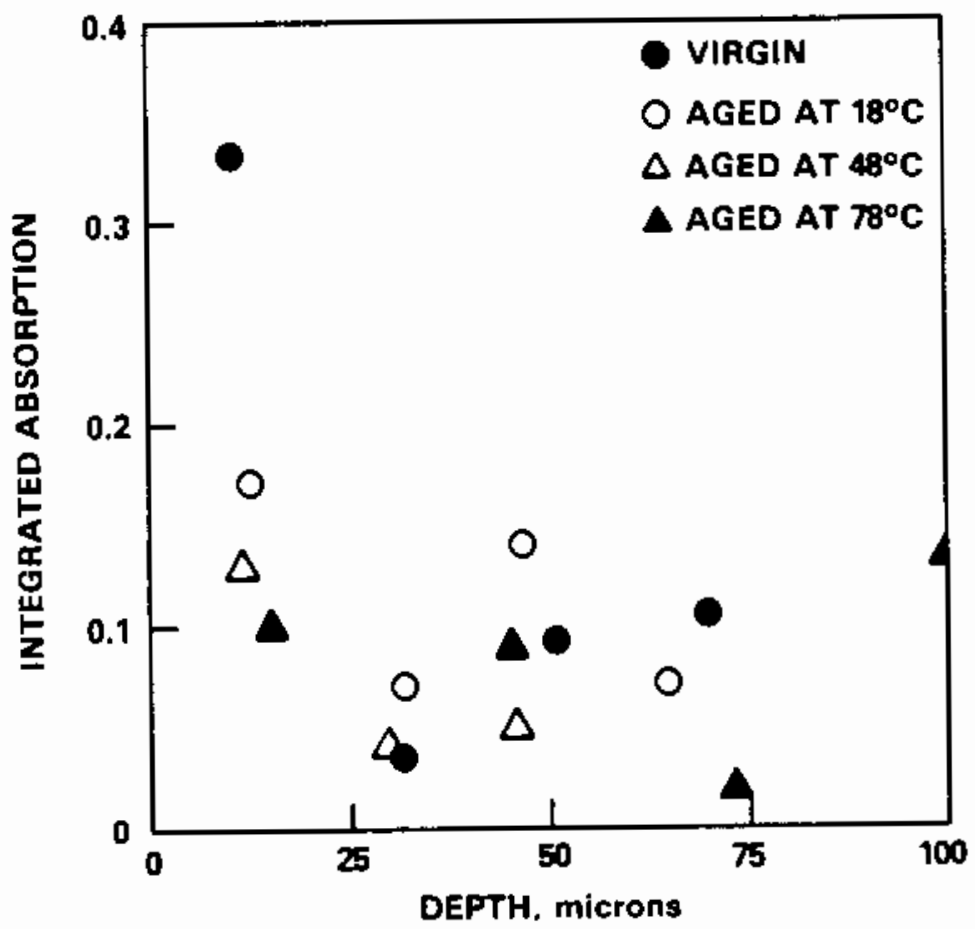

FIGURE 8. Results of Differential Infrared Analysis of Aged High Density Polyethylene Samples Indicating Relative Carbonyl Concentrations

The latter explanation is being investigated further; however, no surface attack was visible, and the thickness and density of the high density polyethylene remained unchanged in all three exposure columns.

Seam test results on aged high density polyethylene are given in Table 11. The seam was a fillet-type extrusion weld. In all cases the sample yielded at locations other than the seam; therefore, these tests also double as yield tests. The results in Table 12 show a slight increase in the yield stress with aging and no decline in seam strength.

In contrast to the apparent relative inertness of the high density polyethylene liner, the polyvinyl chloride liners underwent some chemical reactions as evidenced by oxygen consumption in the $48^{\circ} \mathrm{C}$ column and oxygen consumption coupled with hydrogen generation in the $78^{\circ} \mathrm{C}$ column. We expect to see significant chemical changes in the chemical analyses of the polyvinyl chloride samples. 

TABLE 11. Results of Shear Tests on Fillet-Welded Lag Seams of
Virgin and Aged High-Density Polyethylene

$\begin{array}{lc}\text { Sample } & \text { Yield Stress, dynes } \\ { } } & 2218 \\ \text { Aged at } 18^{\circ} \mathrm{C} & 2536 \\ \text { Aged at } 48^{\circ} \mathrm{C} & 2779 \\ \text { Aged at } 78^{\circ} \mathrm{C} & 2844\end{array}$

(a) All samples yielded at locations other than the seams. The results are averages of three tests. See Appendix B for test procedures.

TABLE 12. Results of Tear Tests on Virgin and Aged High Density Polyethylene

$\begin{array}{ll}\frac{\text { Sample }}{\text { Virgin }} & \frac{\text { Tear Force, N }}{139 \pm 9} \\ \text { Aged at } 18^{\circ} \mathrm{C} & 135 \pm 8 \\ \text { Aged at } 48^{\circ} \mathrm{C} & 147 \pm 6 \\ \text { Aged at } 78^{\circ} \mathrm{C} & 149 \pm 10\end{array}$




\section{ANOMALY CONFORMANCE TESTS}

The objective of these tests is to compare the performance of virgin and aged geomembranes when stressed over anomalous features typical of those which may actually exist in the field. This section will discuss related work in this area, the experimental procedure used for this task, and the results obtained to date.

RELATED WORK

The ability of a geomembrane to conform to an anomalous subgrade is an important feature in subgrade design and specification. Anomalous features such as rocks, ruts, cracks, and structures can potentially puncture the liner. Materials which are more prone to rupture or perforate when stressed will require extra care in engineering of the subgrade.

Unfortunately there is no accepted standard test available to measure the liner resistance to failure by anomalous subgrade features. Illustrating this point, Hickey (1969) states that in testing liners over a rock subgrade, the best performer was polyvinyl chloride, followed by ethylene-vinyl acetate copolymer, chlorinated polyethylene (Feinforced), and polyethylene. However, in Elmendorf puncture resistance tests, the four materials were ranked in a different order: polyvinyl chloride, reinforced chlorinated polyethylene, polyethylene, and ethylene-vinyl acetate. The difference in apparent puncture resistance is apparently due to different stress rates and concentrations in the two tests.

Rigo (1978) has studied the phenomenon of failure geomembranes over anomalous features. In his analysis, one mode of fallure is perforation over a sharp point, and the second is bursting between two high points. He has tested geomembranes with pressure over rocks and found nonreproducible results due to shifting of rocks. His test procedure consisted of increasing pressure by $1 \mathrm{~kg} / \mathrm{cm}^{2}$ increments in 15 seconds and then holding at constant pressure for 45 seconds. Pressure is again increased using these increments and intervals until the membrane bursts. 
The Bureau of Reclamation (Frobel 1981; Hickey 1969; Morrison et al. 1981) has investigated failure of geomembranes over rocks in both the laboratory and the field. Their laboratory test device is automated to increase pressure by $0.15 \mathrm{~kg} / \mathrm{cm}^{2}$ every 4 hours.

\section{EXPERIMENTAL}

We have constructed a device operating on the same principle as the previously discussed systems. A schematic of the device is shown in Figure 9. The tester is made of $0.25-m$ pipe flanges and pipe caps. To prevent shifting of rocks between tests, an epoxy glue was poured over rocks in the tester, forming a conglomerate piece without affecting the surface features. The rock size

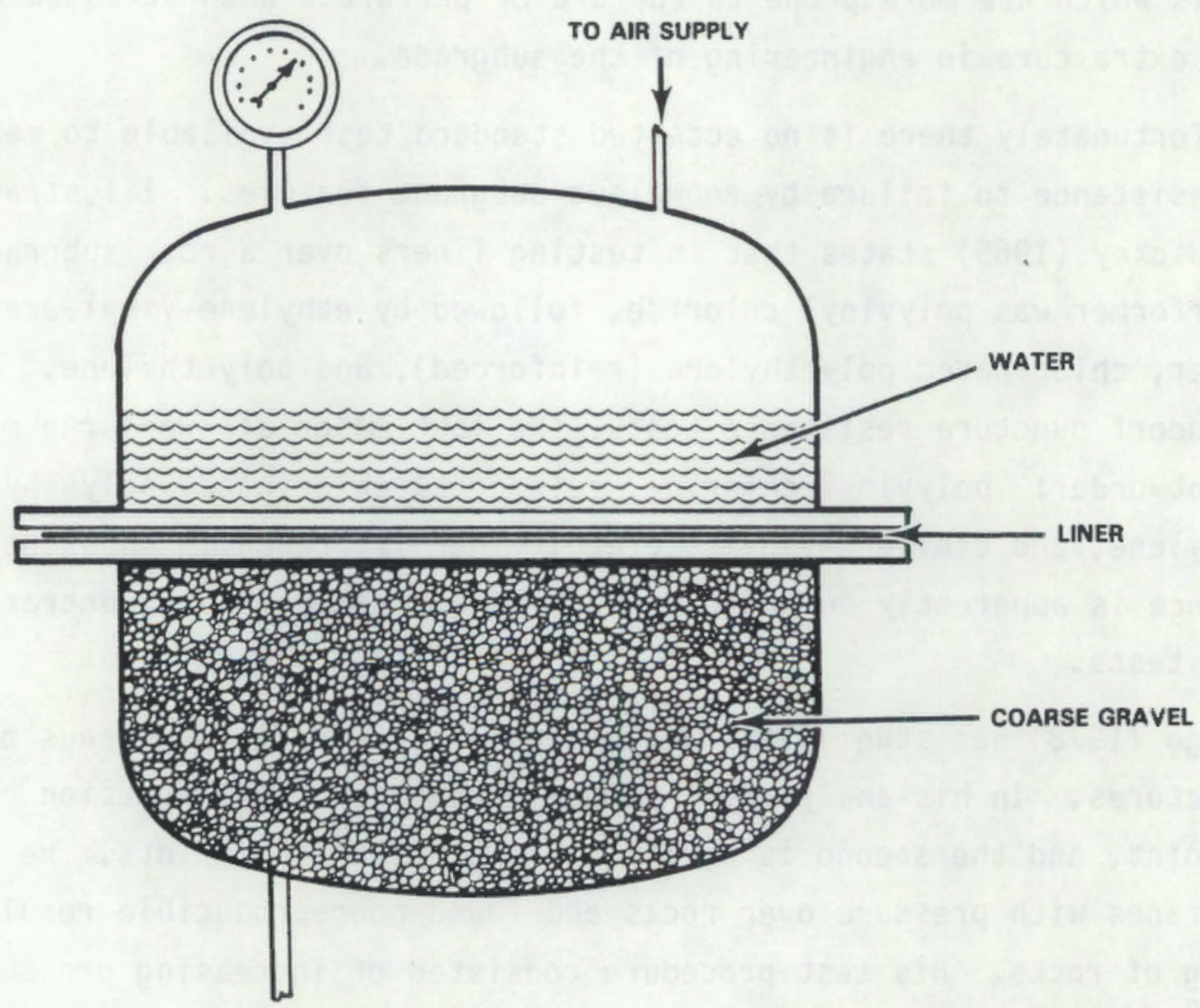

FIGURE 9. Schematic of Anomaly Conformance Test Device 
ranged between 19 and $38 \mathrm{~mm}$ in diameter. Some rocks were round and some were sharp. A mixture of round and crushed rock in the size range of 19 to $38 \mathrm{~mm}$ is used in the test device.

The following test procedure is used:

1. Place membrane in tester. If the piece is seamed, align the seam in the same orjentation for each test. Install the top flange.

2. Pour water into the top so the liner is completely covered. The water provides the operator rapid and positive detection of membrane failure. Open the bottom drain valve.

3. Increase the pressure by 10 psig in 30 seconds and maintain this pressure for an additional 4.5 minutes. Repeat this step until the liner fails or until 100 psig is reached. Hold pressure at 100 psig for 10 minutes, then slowly bleed off the pressure.

4. Record the time and pressure when the liner fails.

5. Remove the liner from the column and inspect the liner over a bright light, recording the number of holes and the type of failures.

\section{RESULTS}

Results of the high density polyethylene tests are presented in Table 13. Increased exposure temperatures do not significantly affect the performance of the high density polyethylene.

The failures were most commonly due to stress concentration at a sharp rock, followed by elongation and rupture. The failure pressure (50 psig) would be equivalent to $35 \mathrm{~m}(115 \mathrm{ft})$ of liquid head or about $12 \mathrm{~m}(40 \mathrm{ft})$ of tailings covered by $11 \mathrm{~m}(35 \mathrm{ft})$ of leachate.

The same tests with polyvinyl chloride show a decline in its performance in the sample aged at $78^{\circ} \mathrm{C}$. Where all the other polyvinyl chloride samples failed by rips on sharp rocks at $100 \mathrm{psig}$, the sample aged at $78^{\circ} \mathrm{C}$ failed by a crack in a fold on the material at 60 psig. The crack probably was caused by loss of plasticizer and degradation of the polyvinyl chloride. Chemical analyses are underway which should support this claim. 
TABLE 13. Results of Tests Stressing 1 mm High Density Polyethylene and $0.91 \mathrm{~mm}$ Polyvinyl Chloride Over a Rocky Subgrade

\section{Failure}

Sample Pressure, psig

Comment

High Density Polyethylene (1 $\mathrm{mm}$ )

$\begin{array}{lcl}\text { Virgin } & 60 & 2 \text { holes, } \sim 3 \mathrm{~mm} \text { dia ea. } \\ \text { Virgin } & 50 & 2 \text { holes, } \sim 3 \mathrm{~mm} \text { and } 2.4 \mathrm{~mm} \mathrm{dia} \\ \text { Virgin, seamed } & 50 & 1 \text { hole, } \sim 4 \mathrm{~mm} \text { dia } \\ \text { Virgin, seamed } & 50 & 1 \text { hole, } \sim 3 \mathrm{~mm} \text { dia } \\ 18^{\circ} \mathrm{C} \text { exposure, seamed } & 60 & 1 \text { hole, } \sim 3 \mathrm{~mm} \text { dia } \\ 48^{\circ} \mathrm{C} \text { exposure, seamed } & 60 & 1 \text { hole, } \sim 1 \mathrm{~mm} \text { dia } \\ 78^{\circ} \mathrm{C} \text { exposure, seamed } & 50 & 1 \text { hole, } \sim 1 \mathrm{~mm} \text { dia } \\ \text { Polyvinyl Chloride }(0.91 \mathrm{~mm}) & \\ \text { Virgin } & 100 & 1 \text { rip, } 16 \mathrm{~mm} \text { long } \\ \text { Virgin } & 100 & 1 \text { rip, } 2 \mathrm{~mm} \text { long } \\ \text { Virgin, seamed } & 100 & 1 \text { rip, } 13 \mathrm{~mm} \text { long } \\ \text { Aged at } 18^{\circ} \mathrm{C} & 100 & 1 \text { rip, } 16 \mathrm{~mm} \text { long } \\ \text { Aged at } 48^{\circ} \mathrm{C} & 100 & 1 \text { very sma } 11 \text { hole } \\ \text { Aged at } 78^{\circ} \mathrm{C} & 60 & 1 \text { crack, } 32 \mathrm{~mm} \text { long }\end{array}$

One word of caution is advised. These tests were performed over intervals of 30 to 40 minutes each. They are intended to serve as a comparison of properties as a function of aging and for comparisons between different materials. The long-term performance of liners exposed to lower stresses has not been demonstrated. 
From the information assembled in this report, recommendations will be made for design, installation, and inspection techniques for uranium mill ponds with flexible menbrane liners. A report with recommendations will be issued to assist mill licensing personnel.

Simulated aging of chlorosulfonated and chlorinated polyethylene liners will be completed. Chemical and physical tests on all aged liner materials will be completed. Aging kinetics will be analyzed and the amount of simulated aging of each material will be determined. A report on material selection based on these tests will be issued to assist mill licensing personnel. The report will include detailed test procedures. 



\section{REFERENCES}

Baldwin, R. D. 1983. "Lining a Pond to Contain Uranium Tajlings." Civil Engineering - ASCE 53(1):77-79.

Biggs, B. S. 1953. "Aging of Polyethylene." In Polymer Degradation Mechanisms, pp. 137-143. NBS Circular 525, Nationa 7 Bureau of Standards, Washington, D.C.

Billmeyer, F. W., Jr. 1971. Textbook of Polymer Science. John Wiley and Sons, New York.

Buelt, J.L. and S. M. Barnes. 1983. Aging Test Results of an Asphalt Membrane Liner. PNL-4752, Pacific Northwest Laboratory, Richland, Washington.

Collins, T. G. and D. D. Newkirk. 1982. "The Use of Geotextile Fabrics in Pond Construction Beneath an Impermeable Membrane." In Proceedings of Second International Conference on Geotextiles, Las Vegas, Nevada.

Frobe1, R. K. 1981. Design and Development. of an Automated Hydrostatic Flexible Membrane Test Facility. REC-ERC-80-9, U.S. Bureau of Reclamation, Denver, Colorado.

Gee, G. W., A. C. Campbel1, B. E. Opitz, and D. R. Sherwood. 1980. "Interaction of Uranium Mill Tailings Leachate with Morton Ranch Clay Liner and Soil Mineral." In Symposium on Uranium Mill Tailings Management, pp. 333-352, Colorado State University, Fort Collins, Colorado.

Giroud, J. P. 1982. "Design of Geotextiles Associated with Geomembranes." In Proceedings of Second International Conference on Geotextiles, Las Vegas, Nevada.

Giroud, J.P. and J. S. Goldstein. 1982. "Geomembrane Liner Design." Waste Age, September 1982, pp. 27-30.

Giroud, J. P., and P. Huot. 1977. "Conception Des Barrages en Terre et Enrochements Munis D'Entancheme Par Feville Mince." Presented at Conference Europeenne de la CIID, Rome.

Haxo, H., Jr. 1980. Lining of Waste Impoundment and Disposal Facilities. EPA/530/SW-870C, U.S. Environmental Protection Agency, Cincinnati, Ohio.

Hickey, M. E. 1969. Investigations of Plastic Films for Canal Linings. A Water Resources Technical Publication, Research Report 19. U.S. Dept. of Interior, Washington, D.C. 
Huck, P. J. 1982. "Assessment of Time Domain Reflectometry and Acoustic Emission Monitoring: Leak Detection Systems for Landfill Liners." In Proceedings of the $8 \mathrm{th}$ Annual Research Symposium on Land Disposal of Hazardous Waste, PP. 261-273. EPA 600/9-82-002, U.S. Envíronmental Protection Agency, Cincinnati, Ohio.

Kays, W. B. 1977. Construction of Linings for Reservoirs, Tanks, and Pollution Control Facilities: John Wiley and Sons, New York.

Morrison, W. R., E.W. Gray, Jr., D. B. Paul, and R. K. Frobel. 1981. Installation of Flexible Membrane Lining in Mt. Elbert Forebay Reservoir. REC-ERC-8Z-Z, U.S. Bureau of RecTamation, Denver, Colorado.

Myers, C. S. 1952. "Oxidation of General Purpose Polyethylene Resin." Industrial and Engineering Chemistry 44(5):1095-1098.

Myers, D. A., S. W. Tyler, P. J. Gutknecht, and D. H. Mitchell. 1983. Leak Detection Systems for Uranium Mill Tailings Impoundments with Synthetic Liners. PNL-4694, Pacific Northwest Laboratory, Richtand, Washington.

Perry, J. H. 1969. Chemical Engineers' Handbook. McGraw Hill, New York.

Peters, W. R., D. W. Shultz, and B. M. Duff. 1982. "Electrical Resistivity Techniques for Locating Liner Leaks." In Proceedings of the 8th Annual Research Symposium on Land Disposal of Hazardous Waste, pp. 250-260. EPA 600/9-82-002, U.S. Environmental Protection Agency, Cincinnati, Ohio.

Rigo, J. M., 1978. "A correlation entre la resistance an Panconnement Sur Ballast et les caracteristiques mechaniques des membranes d'etancheite. Considerations sur leurs modes de ruine." Materiaux et Constructions $11(65): 347-359$.

Schnabel, W. 1981. Polymer Degradation. McMilliam Publishing, New York.

Small, D. M. 1980. "Establishing Installation and Material Selection Parameters for Liner Placement Systems." In Proceedings of the Symposium on Uranium Mill Tailings Management, Colorado State University, Fort Collins, Colorado.

U.S. Nuclear Regulatory Comission. 1980. Final Generic Environmental Impact Statement on Uranium Milling. NUREG-D706, Vol. 1, Washington, D.C.

Watersaver. 1982. "PVC Installation Manual." Watersaver Company, Inc., P.0. Box 16465, Denver, Colorado.

Williams, R. E., 1982. A Guide to the Prevention of Groundwater Contamination by Uranium Mill Wastes. Colorado State University Geotechnical Engineering Program, fort Collins, Colorado. 
APPENDIX A

MICROTOME TECHNIQUE FOR

HIGH DENSITY POLYETHYLENE AND

POLYVINYL CHLORIDE 
APPENDIX A

MICROTOME TECHNIQUE FOR HIGH DENSITY POLYETHYLENE AND POLYVINYL CHLORIDE

Samples of both high density polyethylene and polyvinyl chloride have been cut in slices approximately $25-\mu m$ thick from the sample surface to a depth of $100 \mu \mathrm{m}$. These thin slices were analyzed for chemical changes which occur during the aging process. Both virgin and aged plastics were microtomed.

\section{MATERIALS AND SUPPLIES}

- $1 \times 1 \mathrm{~cm}$ square liner samples

- Smooth-faced brass stubs to attach the samples for microtomy

- Adhesive: Elmer's Nonflammable Solvent Contact Cement

- 1,1,1 Trichloroethane solvent for cleanup

- X-acto knife, tweezers, and rubber gloves for sample handling

- Micrometer to measure thickness of slice

- 1 dram vials for storage

- Argon for microtome atmosphere

- Microtome cryostat

- Microtome knives sharpened to a razor edge.

PROCEDURE

1. Glue samples to the brass stubs face up with Elmer's Contact cement. The edges of high density polyethylene samples have a raised surface, which should be trimmed with the $x$-acto knife to obtain a uniform surface. (This is not a problem with polyvinyl chloride.)

2. Turn on the microtome cryostat and refrigerate to $\sim 15^{\circ} \mathrm{C}$.

3. Place an argon purge line in the slicing compartment and set the pressure valve for a slow turnover rate.

4. Put a sharp knife in the holder and permit it to equilibrate to $\sim 15^{\circ} \mathrm{C}$. Make certain that the retaining screws are tight. 
5. When the microtome has cooled sufficiently, place a prepared stub in the holder and tighten the set screw. All set screws must be tight!

6. Orient the block with the base side parallel to the knife edge. Bring the block up to the knife slowly, and with up-and-down strokes carefully align the face of the block with the edge of the knife edge on the block face as you pass the block just behind it. The shadow will remain parallel along the complete face if the block is parallel to the plane of cut. This is a difficult and important step that determines whether a complete section will be obtained on the first slice.

7. When you are satisfied with the plane of the block, make your first cut into the block firmly and smoothly. The depth setting for 25 un on our machine is 6 .

8. Retract the block and tweezers to lift the section from the face. The section will most likely curl and adhere to the top edge. Carefully cut the section off the biock with an $x$-acto knife and uncurl it over one finger of your gloved hand.

9. Measure its thickness with a micrometer.

10. Purge a 1-dram vial with argon and place the section inside. Seal the vial.

You are now prepared to continue slicing the block to the desired depth in consecutive sections from this point.

\section{SPECIAL INSTRUCTIONS}

It is important to handle the sample liner, slices and equipment with rubber gloves or clean utensils to prevent the introduction of any foreign material to the sample. Keep the door shut to the compartment filled with argon unless microtoming. Handle the sections within the argon atmosphere as much as possible before rather than after sealing them in the vial. Argon is heavier than air so the sections can be held down in the compartment atmosphere to reduce any exposure to oxygen. 
Polyvinyl chloride can be cut at room temperature as well as at $-15^{\circ} \mathrm{C}$. High density polyethylene, however, cannot be cut easily at room temperature.

The orientation of the block face to the knife edge is extremely important because the first slice will be incomplete if it is not parallel to the cutting plane. Also, the following slices taken from the block will not be at the respective uniform depth. This facing of the block is aggravated by scratches and bumps on the surface. A judgment must be made as to what will suit your needs.

Keep your knives sharp. A dull knife will skip a slice, compressing the block face and cutting a double thick section on the next pass. A dull knife also has a tendency to unroll the slice cut and on the down stroke reattach the slice to the face, making it very difficult to retrieve.

Because ultraviolet light may age the plastic, keep material in the dark as much as possible. 


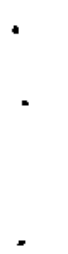

.

. 
APPENDIX B

PHYSICAL TESTING PROCEDURES 


\section{APPENDIX B}

\section{PHYSICAL TESTING PROCEDURES}

High density polyethylene, $1 \mathrm{~mm}$

Polyvinyl chloride, nonreinforced, $0.91 \mathrm{~mm}$

ASTM D882

Tensile strength, elongation, 3 specimens, $5 \mathrm{~cm} / \mathrm{min}$

ASTM D1004

Tear, 3 specimens

ASTM D882, $25 \mathrm{~mm}$ wide by (100 $\mathrm{mm}+$ seam width) separation, $5 \mathrm{~cm} / \mathrm{min}$ Seam Strength

Chlorosulfonated polyethylene, reinforced, $0.91 \mathrm{~mm}$

chlorinated polyethylene, reinforced, $0.91 \mathrm{~mm}$

ASTM 0751

Breaking strength

ASTM D413

Ply adhesion, Type A, $180^{\circ}$ peel, strip specimen, $5 \mathrm{~cm} / \mathrm{min}$

ASTM D751 A Grab Method

Seam Strength, $100 \mathrm{~mm}$ wide by (6 in. + seam width separation), $5 \mathrm{~cm} / \mathrm{min}$ ASTM 0751

Tear Strength, Method B

Specimen $200 \times 200 \mathrm{~mm}$ 
$\cdot$
.
. 
APPENDIX C

COLUMN CONDITIONS DURING HIGH DENSITY

POLYETHYLENE EXPOSURE TESTS 

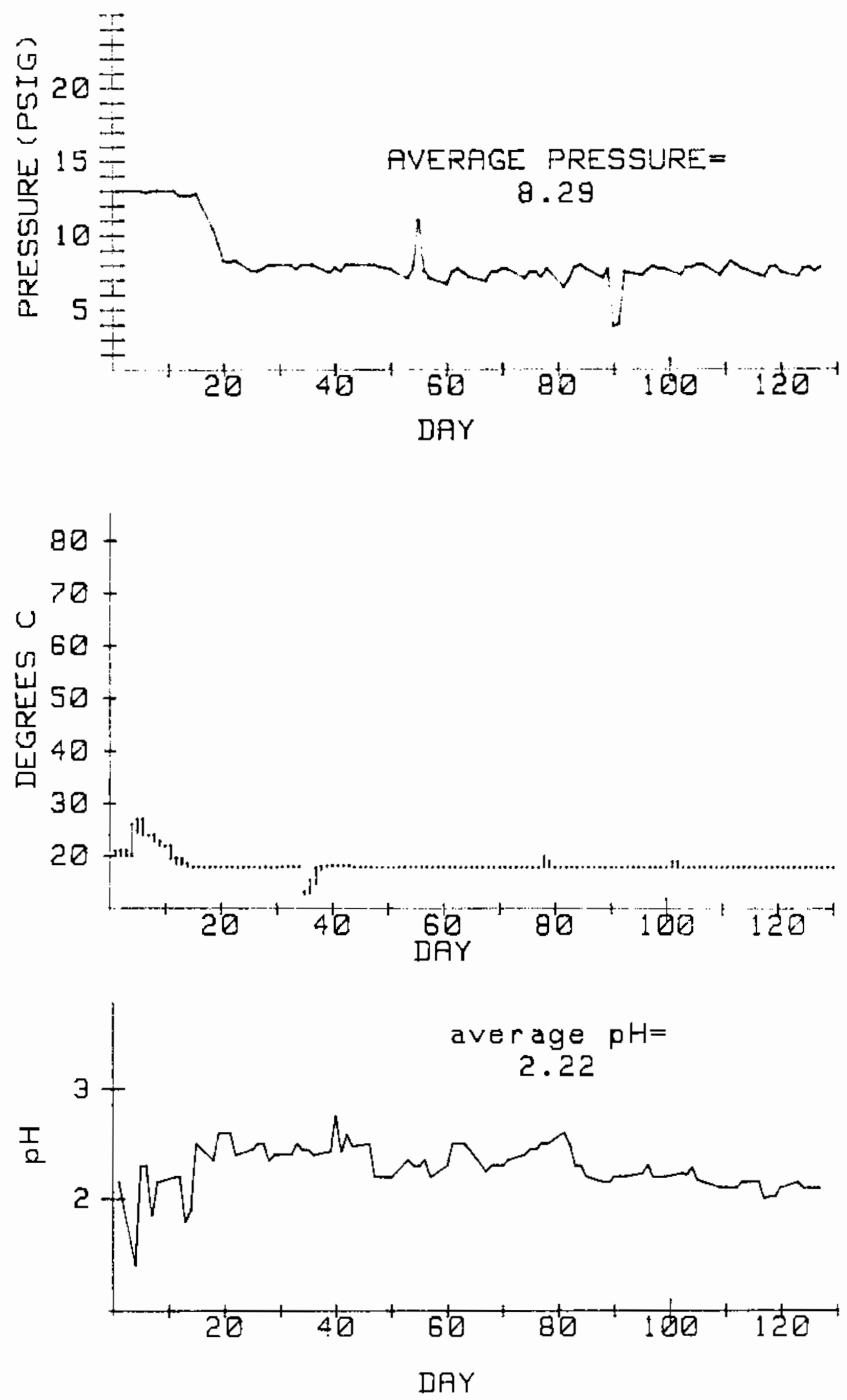

EIGUREC. 1, Exposure Conditions for Aging of high Density Polyethylene at $18^{\circ} \mathrm{C}$

C. 1 

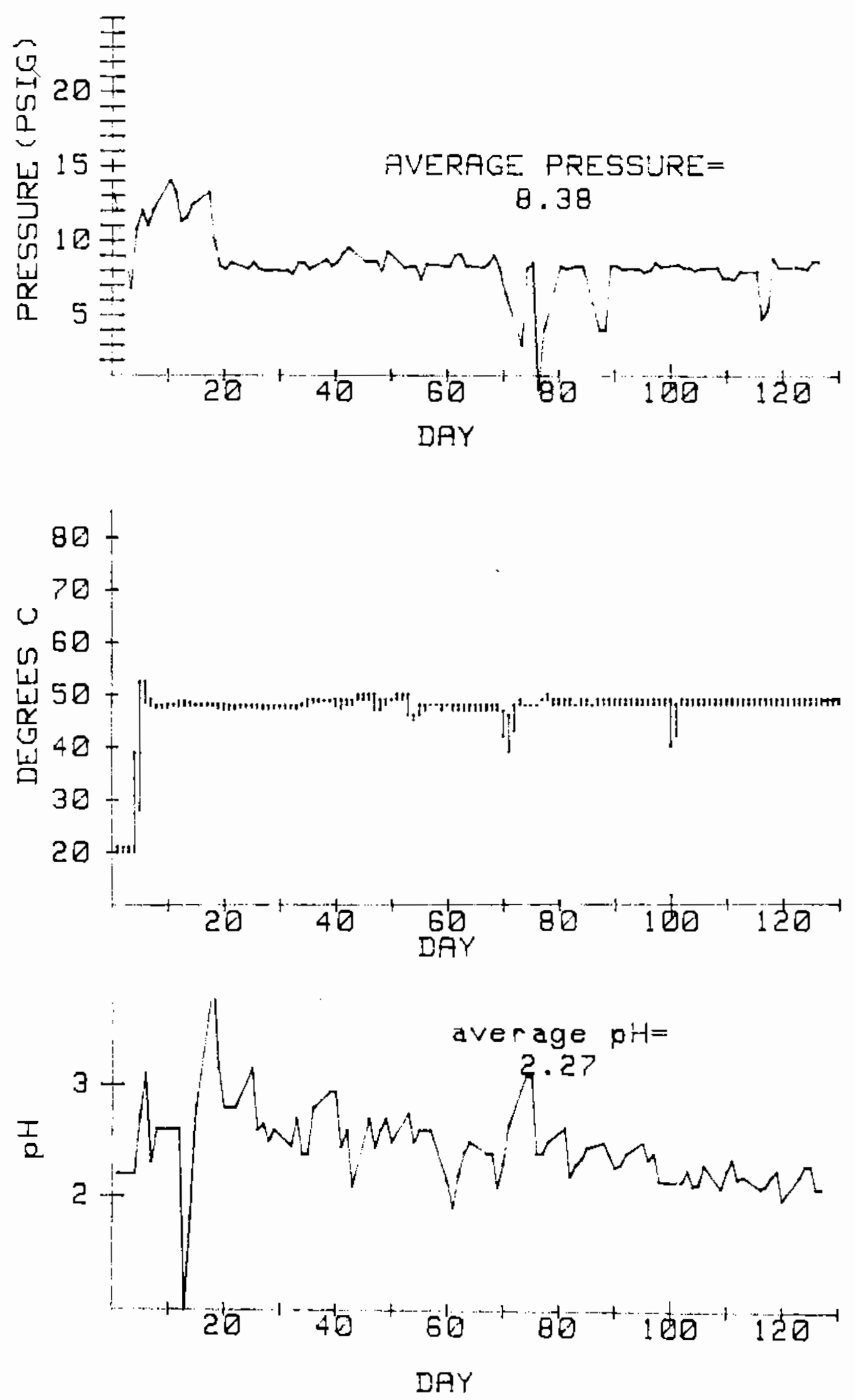

FIGURE C.2. Exposure Conditions for Aging of Hiah Density Polyethylene at $48^{\circ} \mathrm{C}$ 

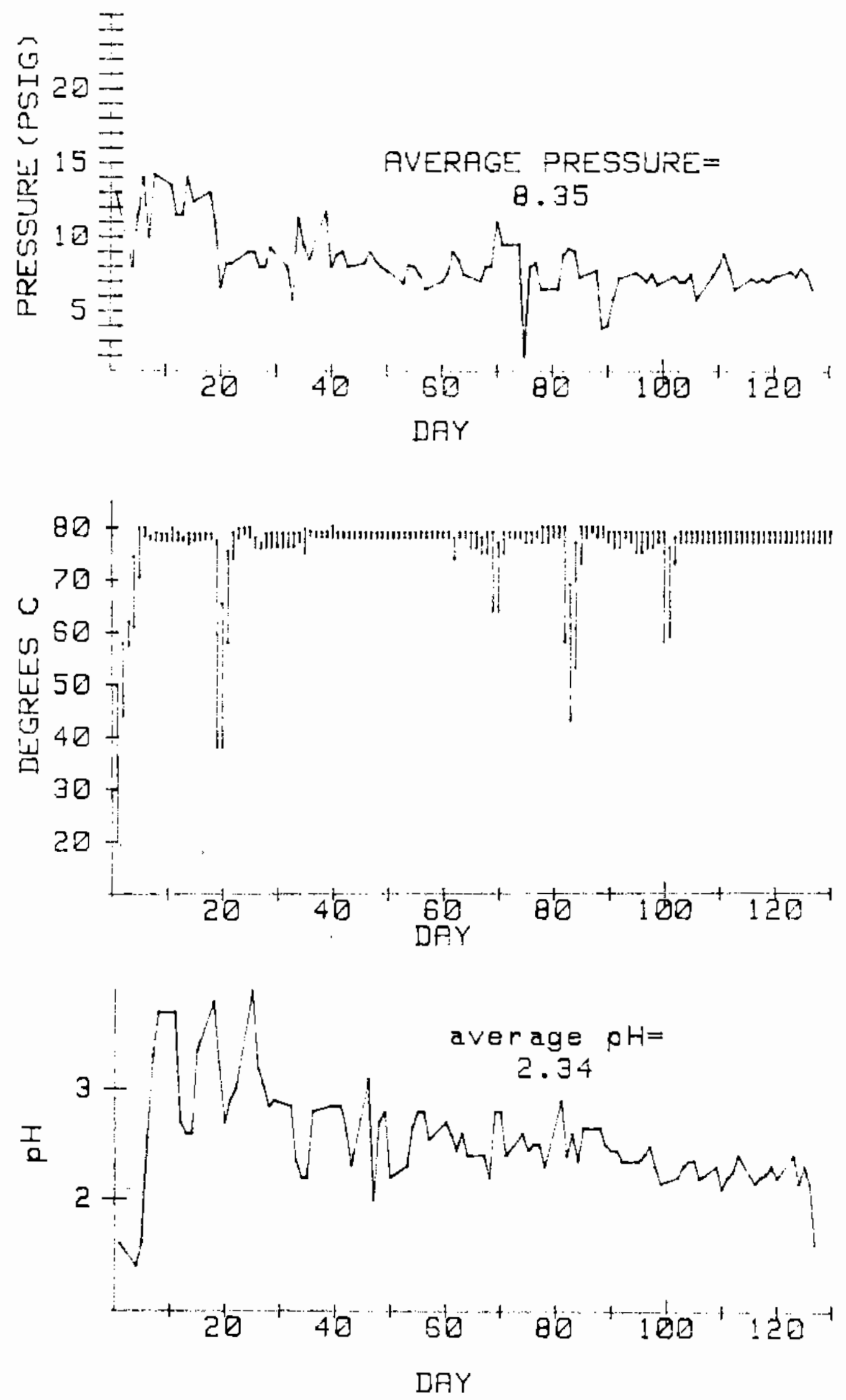

FIGURE C.3. Exposure Conditions for Aqing of High Density Polyethylene at $78^{\circ} \mathrm{C}$

C. 3 
. 
APPENDIX D

SCHEMATICS FOR FAULTY SEAMS FOR

SEAM INSPECTION TESTS 


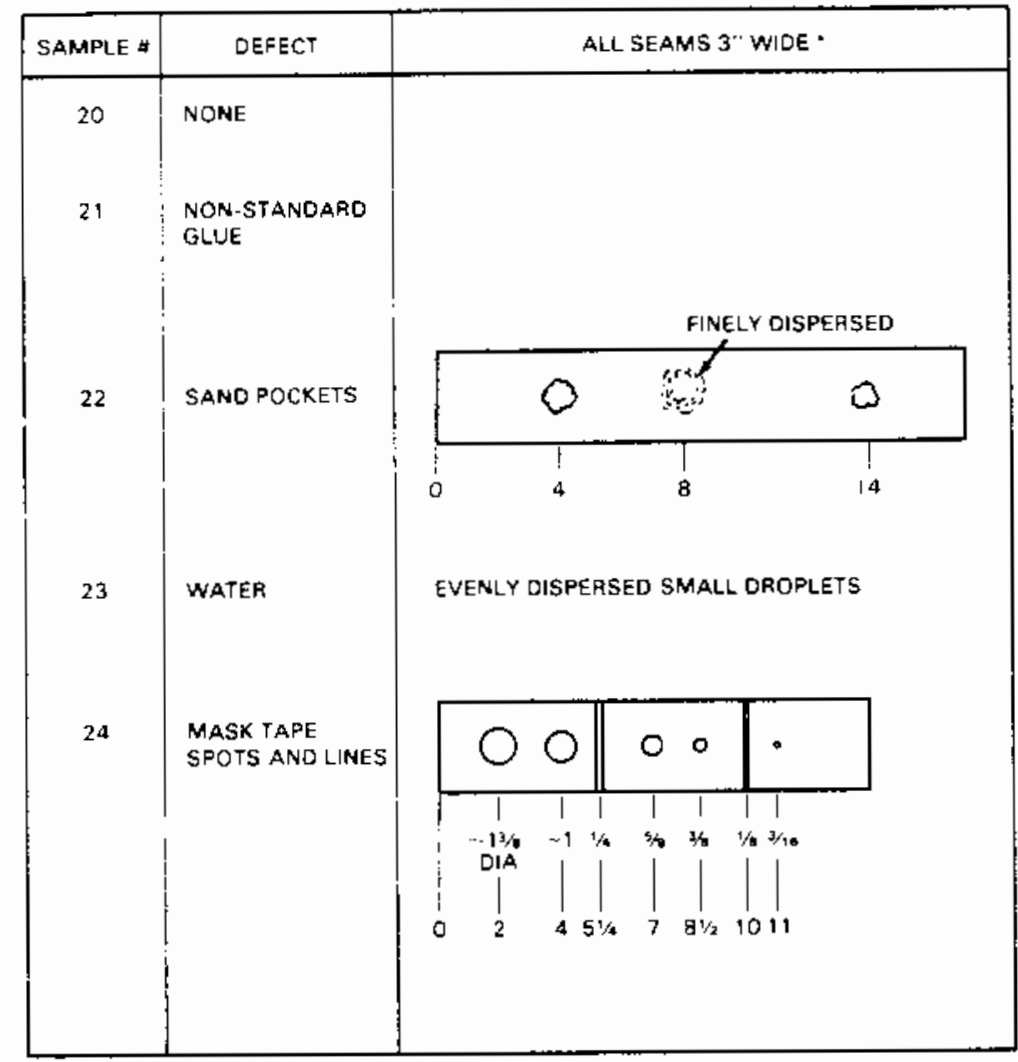

-aLl MEASUREMENTS IN INCHES

FIGURE D.1. Schematic of Intentional Flaws in Seam Samples of Polyvinyl Chloride 


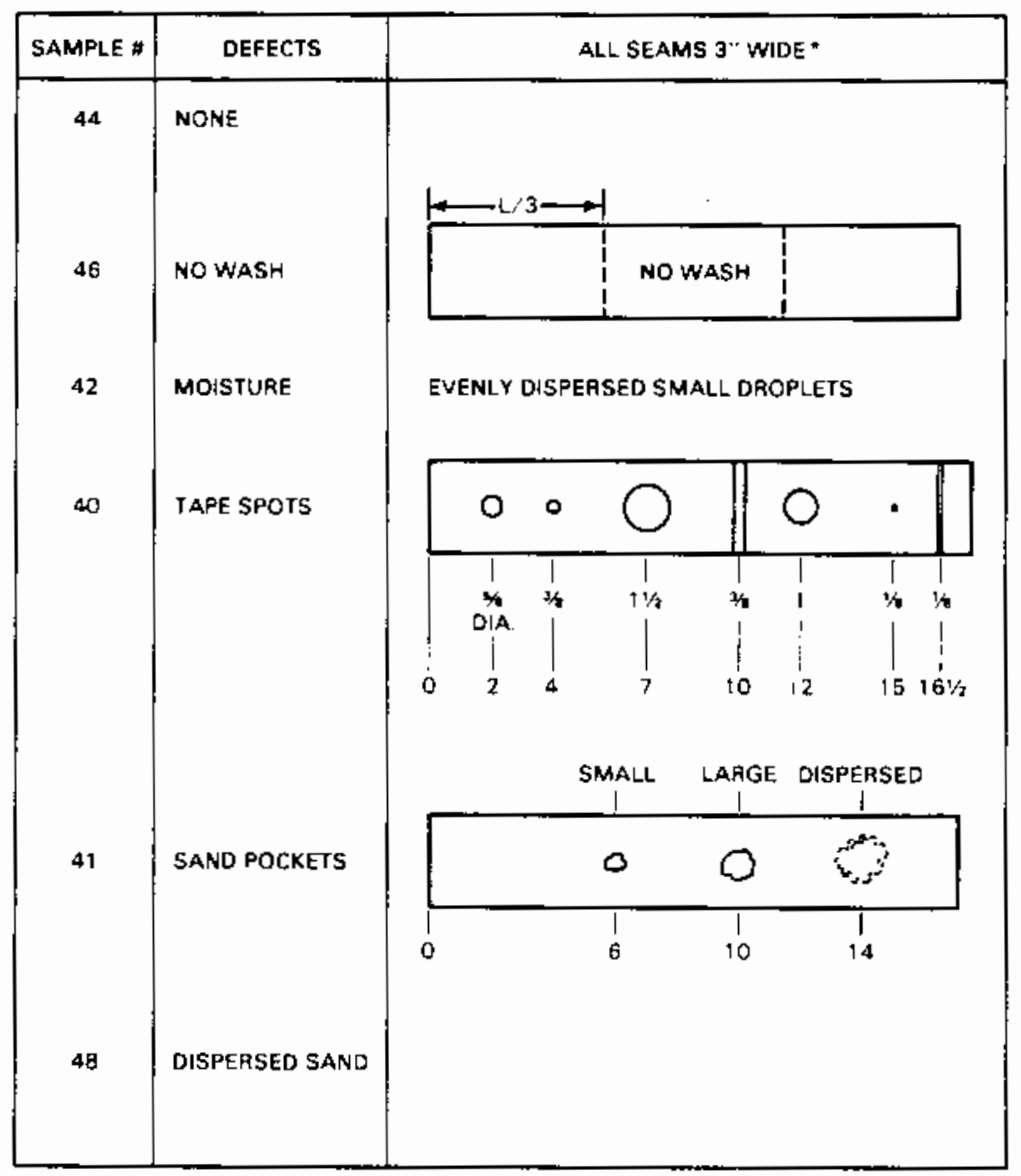

-ALL MEASUREMENTS IN INCHES

FIGURE D.2. Schematic of Intentional Flaws in Seam Samples of Reinforced $\mathrm{Chl}$ orosulfonated Polyethylene 


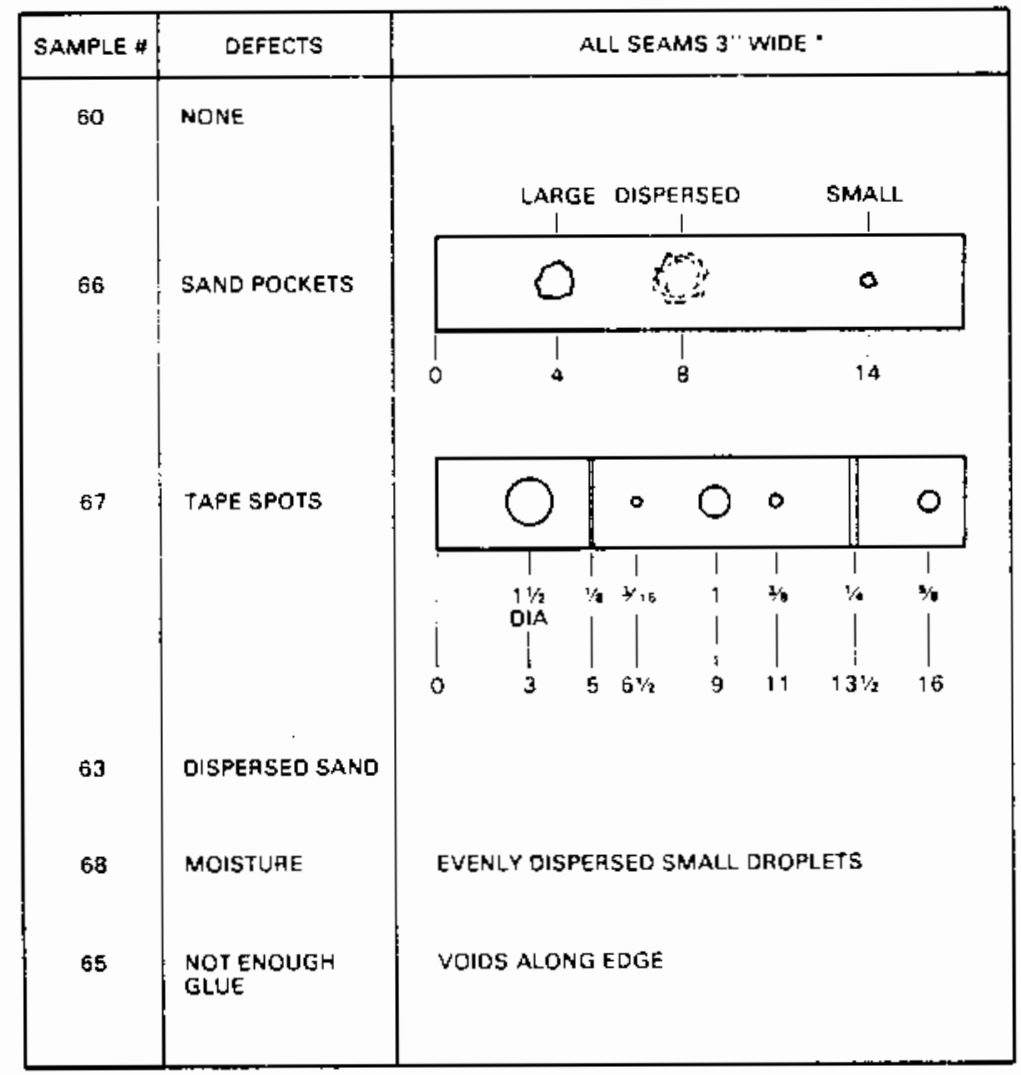

*ALL MEASUREMENTS IN INCHES

FIGURE 0.3. Schematic of Intentional Flaws in Seam Samples of Reinforced Chlorinated Polyethylene 
• 


\section{DISTRIBUTION}

No. of

Copies

OFFSITE

27 DOE Technical Information Center

5 R. A. Pennifill

Low-Level Waste Licensing Branch

U.S. Nuclear Regulatory Commission

Mailstop 632-SS NRC

Washington, DC 20555

3 Municipal Environmental Research Laboratory

U.S. Environmental Protection Agency

26 W. St. Clair St.

Cincinnati, OH 45268

ATTN: M. Curran

R. Hart ley

R. Landreth

2 U.S. Bureau of Reclamation

Denver Federal Center

Building 67

Denver, CO 80223

ATTN: R. K. Frobel

L. 0. Timblin
No. of

Copies

ONSITE

DOE Richland Operations Office

H. E. Ransom

27 Pacific Northwest Laboratory

S. M. Barnes

W. F. Bonner

J. L. Buelt

T. D. Chikalla

M. G. Foley

G. W. Gee

N. R. Gordon

J. N. Hartiey

S. E. King

J. R. Morrey

D. H. Mitchell (5)

D. A. Myers

G. E. Spanner (4)

Technical Information (5)

Publishing Coordination cg (2)

2 U.S. Nuclear Regulatory Commission

Division of Technical

Information and Document Control

7920 Norfolk Ave.

Bethesda, MD 20014 


\author{
.
}

